\title{
Morphology and distribution of the external labial sensilla in Fulgoromorpha (Insecta: Hemiptera)
}

\author{
Jolanta Brożek • Thierry Bourgoin
}

Received: 24 May 2012/Revised: 24 August 2012/ Accepted: 30 August 2012/Published online: 30 September 2012

(C) The Author(s) 2012. This article is published with open access at Springerlink.com

\begin{abstract}
The present paper describes the sensory structures on the apical segment of the labium in fifteen fulgoromorphan families (Hemiptera: Fulgoromorpha), using the scanning electron microscope. Thirteen morphologically distinct types of sensilla are identified: five types of multiporous sensilla, four types of uniporous sensilla and four types of nonporous sensilla. Three subapical sensory organ types are also recognized, formed from one to several sensilla, each characteristic of a family group. Sensilla chaetica (mechanoreceptive sensilla) fall into three categories dependent on length and are numerous and evenly distributed on the surface of the labium except where they occur on specialized sensory fields. The planthopper morphological ground plan is represented by two apical pair of sensory fields (dorsal and ventral) on which 11 dorsal pairs of sensilla (10 peg-like pairs +1 specialized pair dome or cupola-like) and 2 ventral pairs of sensilla basiconica occur. Two main patterns (cixiid and issid) together with more specialized ones (derbid, lophopid, flatid and fulgorid) are reported. Disparity and diversity of the sensory structures are analyzed from a taxonomic and functional perspective. A gustatory function is provided for several chemoreceptive labial sensilla, as in the antennal flagellum
\end{abstract}

Communicated by A. Schmidt-Rhaesa.

\section{J. Brożek ( $₫)$}

Department of Zoology, University of Silesia, Bankowa 9, 40-007 Katowice, Poland

e-mail: jolanta.brozek@us.edu.pl

\section{T. Bourgoin}

Département Systématique and Evolution, Museum National d'Histoire Naturelle, UMR 7205, MNHN-CNRS, 45 rue Buffon, 75005 Paris, France

e-mail: bourgoin@mnhn.fr sensilla in some other Hemiptera. This represents a more recently evolved function for the planthopper labium. Finally, further lines of study are suggested for future work on the phylogeny of the group based on the studied characters.

Keywords Fulgoromorpha · Apex labium · Labial sensilla distribution · Phylogeny · Gustatory function . Exaptation

\section{Introduction}

Insect sensilla consist of an exocuticular outer structure by or through which stimuli are conveyed to one or more sensory cell processes within the sensilla. Shape and size of the cuticular outer structures vary, but most sensilla appear as hairs or pegs. In such sensilla, the socket region can be distinguished from the shaft of the hair or peg (Altner and Prillinger 1980). When sensilla have been examined on the insect body, antennal and mouthpart sensilla have attracted the most attention.

In insects, the antennae represent the primarily sensory structures and are usually richly endowed with sensilla. Most of these are generally distributed on the flagellum and exhibit a variety of forms and characteristics in relation to their various functions of contact chemoreception, mechanoreception and thermohygroreception (Chapman 1998). With regards Fulgoromorpha, most studies on antennal sensilla have focused on putative olfactory sensilla, located on the pedicel (reviewed in Bourgoin and Deiss 1994; Stroiński et al. 2011). Indeed, planthopper flagellum sensilla are less in number than in many other insect, and it is of interest that typical chemoreceptors seem to be absent. This absence is probably compensated for by the olfactory 
sensilla of the pedicel. In this respect, the low number of sensilla on the flagellum should be regarded as a possible functional specialization of the flagellum itself (Romani et al. 2009).

In Hemiptera, the mouthparts have evolved into a rostrum consisting of a short, conical and dorsal labrum and a longer segmented labium, bisected by a stylet groove within which lie the outer mandibular and inner maxillary stylets. The labial tip is bilobed with each right and left lobe exhibiting symmetrically distributed sensilla grouped into sensory fields (Foster et al. 1983b; Backus 1985). There are no chemoreceptors on the stylets that enter the tissue of the host. The only sensilla associated with the food canal are those of the cibarium (Foster et al. 1983a) and precibarium (Backus and McLean 1982, 1983, 1985). Consequently, the insects do not taste the food they are about to feed on until they begin to ingest it. In fact, the majority of the chemoreceptors found on the labium in Hemiptera are in a position enabling them only to monitor chemicals from the external surface of the host (Miles 1958; Backus 1988; Chapman 1995). For these primarily phytophagous insects, these labial sensilla provide the only direct link with the host-plant (Cobben 1988), and it is supposed that the receptors found in the labial tip provide the insects with information that influences their subsequent feeding behavior (Foster et al. 1983b). Labial sensilla might therefore selectively reflect evolution of these host-plant patterns and relationships (Attié et al. 2008) and simultaneously reflect the phylogenetical evolution of the group; accordingly, their study should bring some taxonomic/phylogenetic signal that has not yet been tested with respect to these issues.

The labial sensilla of most hemipterans can apparently perform both chemosensory and mechanosensory functions, while dabbing with the labium, during plant surface exploration. According to Backus (1988), Heteroptera and Auchenorrhyncha are rather similar in their labial sensory system while these two groups show a greater diversity and variability than in Sternorrhyncha while Cobben (1988) indicated more diversity than expected, in Fulgoromorpha. In the latter group, the structure, function and classification of labial sensilla have been precisely studied in only two delphacid crop pests, Nilaparvata lugens by Foster et al. (1983a, b) and Peregrinus maidis by Backus (1985), and found to be similar. A very brief description of the labial sensillae was also published for another delphacid, Tagosodes orizicolus (Mora et al. 2001). In addition, a special subapical sensory organ was first reported by Sogawa (1977) and formally recognized by Cobben (1988) in various species in delphacids, dictyopharids and tettigometrids but probably absent in fulgorids. The purpose of this study is to investigate these and new characters referred to here as the labial sensory apparatus with the objectives of (1) completing a systematic description of the sensory structures and provide a terminology for future work and (2) to evaluate the usefulness of these characters for identifying taxa and for phylogenet studies in Fulgoromorpha.

\section{Materials and methods}

The study was based on dry material from the collections of the Museum National d'Historie Naturelle in Paris (MNHN). SEM photographs were taken from various species representing 15 families of Fulgoromorpha. The list of examined species is provided in Table 3. In the species marked with an asterisk (*), only the sub-apical sensilla were analyzed.

The specimens were coated in gold-palladium and photographed with a Jeol JSM 840 A.

The tips of the chemoreceptor dendrites can be covered by a viscous fluid (containing mucopolisacharides), which sometimes exudes through the terminal pore or wall pores of the sensillum (Chapman 1998). This was observed in the SEM photographs as artefacts visible on or around the peg gustatory, olfactory or contact-chemoreceptive sensilla.

Terminology Sensilla of insects occur in two classes as mechanosensitive or chemosensitive sensilla. Their terminology varies according to their function and morphology including ultrastructure, systems and features that do not overlap. The external morphology is based on the criteria established by Altner and Prillinger (1980), Zacharuk (1980) and Foster et al. (1983b). The different types of sensilla are given with their abbreviations (manly from Brożek and Chłond 2010) in Tables 1 and 2.

\section{Results}

Distribution of the sensilla on the apical segment of the labium

In planthoppers, the labial sensory apparatus is formed by a set of subapical and apical sensilla that show a wide diversity of cuticular structures and organization. They are distributed in various sensory fields and in different locations. Their topography allows us to recognize the following two main groups.

\section{Apical sensilla on the tip of the labium}

In most cases, these sensilla are located in sensory fields (SF) that are clearly differentiated from the rest of the 
Table 1 Terminology and definition of sensilla used in the present paper

\begin{tabular}{|c|c|c|c|}
\hline Category & Function & Pore & Sensilla type \\
\hline $\begin{array}{l}\text { Contact-chemoreceptive } \\
\text { sensilla (bimodal } \\
\text { sensilla) }\end{array}$ & $\begin{array}{l}\text { Gustatory } \\
\text { and tactile }\end{array}$ & $\begin{array}{l}\text { UP: uniporous with } \\
\text { one (sub-) apical } \\
\text { pore }\end{array}$ & $\begin{array}{l}\text { Sensilla basiconica: bristle- (BRSN1, BRSN2) or cone-like sensilla (BSN1, } \\
\text { BNS2) with a flexible basal socket; 3-10 internal sensory neurons } \\
\text { (Chapman 2003) }\end{array}$ \\
\hline Chemoreceptive sensilla & Gustatory & $\begin{array}{l}\text { UP: uniporous with } \\
\text { one terminal pore }\end{array}$ & $\begin{array}{l}\text { Peg-like (PGSU1, PGSU2, PPSU) or clavate-like sensilla (CLSU), in an } \\
\text { inflexible socket; } \\
\text { 3-10 internal sensory neurons (Chapman 2003) }\end{array}$ \\
\hline Chemoreceptive sensilla & $\begin{array}{l}\text { Olfactive } \\
\text { and/or } \\
\text { thermic }\end{array}$ & MP: multiporous & $\begin{array}{l}\text { Variously shaped sensilla (OPSM, CUSM, DSSM), peg-like (PGSM, } \\
\text { PGSMC), tubular (ECLT), branched or multilobed (TEBM), placoid } \\
\text { (PFPL). Over the surface but sunken into an inflexible socket }\end{array}$ \\
\hline Mechanoreceptive sensilla & Tactile & $\begin{array}{l}\text { NP: no pore (or one } \\
\text { basal molting pore) }\end{array}$ & $\begin{array}{l}\text { Sensilla chaetica: sharp tip haired sensilla in a basal flexible socket of } \\
\text { various length }(\mathrm{CH} 1, \mathrm{CH} 2, \mathrm{CH} 3) \text {; often with cuticular sculturing }\end{array}$ \\
\hline
\end{tabular}

BSN1 sensillum basiconicum, nonporous, long, BSN2 sensillum basiconicum, nonporous, short, BRSN1 bristle-like sensillum, nonporous, long, $B R S N 2$ bristle-like sensillum, nonporous, short, OPSM oval plate sensillum, multiporous, PGSM peg sensillum, multiporous, PGSMC peg sensilla, multiporous, complex, CUSM cupola-shaped sensillum, multiporous, DSSM dome-shaped sensillum, multiporous, $P P S U$ peg-in-pit sensillum, uniporous (sensillum coeloconicum), PGSU1 peg sensillum, uniporous, long, PGSU2 peg sensillum, uniporous, short, CLSU clavate sensillum, uniporous, $S a-E C L T$, elevated, cone-like to tubular sensillum, $S a-T E B M$ tubular, branched, multilobated sensillum; $S a-P F P L$ placoid flattened, $S a-P M P L$ placoid, multilobated, sensillum with numerous minute lobes, $\mathrm{CH} 1$ sensillum chaeticum, long, $\mathrm{CH} 2 \mathrm{sensillum}$ chaeticum, medium, $\mathrm{CH}$, sensillum chaeticum, short, $p$ pore, $\mathrm{ml}$ molting pore, $S o c . F l$ flexible sockets, $G r$ grooved surface of sensillum chaeticum, $L g$ labial groove, $S F-D$ dorsal sensory field, $S F-V$ ventral sensory field, $S F-D-A$ dorsal sensory field A, $S F-D-B$ dorsal sensory field B, $M x$ maxillae, $M d$ mandibulae, $R S$ right side of the labial tip, $L S$ Left side of the labial tip

labium tip, forming isolated convex or concave areas. The following two types are recognized: a dorsal sensory field (SFD) situated on each side of the apex of the labial groove and one medial or two paired ventral sensory fields (SFV). Sensilla are usually more numerous on the dorsal rather than ventral fields. Thirteen different morphological types of sensilla have been found on the labial tip (BSN1, BNS2, BRSN1, BRSN2, PGSM, PGSMC, OPSM, CUSM, DSSM, PPSU, PGSU1, PGSU2, CLSU).

\section{Sub-apical sensilla on the labium}

On each side near the tip of the labium, one or more sensilla are present. These correspond to the 'preapical sensory organ' described by Cobben (1988). They are situated into a more or less deep cavity. Three morphologically distinct sensilla types have been recognized (Sa-ECLT, Sa-TEBM, Sa-PFPL). They are multiporous sensilla, usually surrounded by numerous sensilla chaetica $(\mathrm{CH} 1, \mathrm{CH} 2, \mathrm{CH} 3)$.

Morphological characters of the sensilla of the apical segment of the labium

\section{Mechanoreceptive NP sensilla or contact-chemoreceptive UP sensilla: tactile and gustatory sensilla at the tip of the labium}

These sensilla are distinctly inserted within sockets and their bases are flexible. They are wider basally and gradually tapper to apex with the tip slightly rounded. The cuticular walls are smooth with a molting pore near the base (Fig. 1a-d). No terminal pore is visible, and therefore, these sensilla should be considered as mechanoreceptive sensilla. However, their characteristics and location suggest they may be contact-chemoreceptive sensilla with an indistinct terminal pore. While sensilla basiconica (BSN1, BSN2) are present in most fulgoromorpha families examined, bristle-like sensilla (BRSN1, BRSN2) are found only in Fulgoridae. These non-porous(?) sensilla are long, tapered toward apex, end in a fine-spun tip and have a molting pore at their base. The cuticular wall shows evident grooves. Sensilla basiconica and bristle-like sensilla are respectively subdivided into two groups according to their size as follows:

- Large $(10-20 \mu \mathrm{m})$ sensilla basiconica, nonporous (BSN1, Fig. 1a, b). These sensilla were identified in Kinnaridae (Fig. 9e, sensillum no. 13, $L=9.4 \mu \mathrm{m}$ ), Ricaniidae (Fig. 11g, h, sensilla no. 11-16, $L=$ $15.7 \mu \mathrm{m}, L=18.4 \mu \mathrm{m}$ ), Issidae (Fig. 12b, sensilla no. 14, $15, L=11.5 \mu \mathrm{m}$ ), Flatidae (Fig. 13e, f, $L=$ $14.0 \mu \mathrm{m}, L=16.2 \mu \mathrm{m}$ ), Tropiduchidae (Fig. 14c, d, $\mathrm{h}$, sensillum no. $14, \quad L=0.6 \mu \mathrm{m})$, Lophopidae (Fig. 15b, d, h, sensillum no. 34, 35, $L=9.7 \mu \mathrm{m}$ ), Nogodinidae (Fig. 16f-h, sensilla no. 10, 11, 14, 15, $L=11.1 \mu \mathrm{m}, \quad L=9.7 \mu \mathrm{m}) \quad$ and $\quad$ Dictyopharidae (Fig. 17d, h, sensillum no. 12, $L=14 \mu \mathrm{m}$ ).

- Short $(1.0-10 \mu \mathrm{m})$ sensilla basiconica, nonporous (BSN2, Fig. 1c, d). These sensilla were identified in Delphacidae (Fig. 5b, h, sensilla no. 12, 13, $L=4.9 \mu \mathrm{m}$ ), Cixiidae (Fig. 6a, e, sensilla no. 12, 13, 


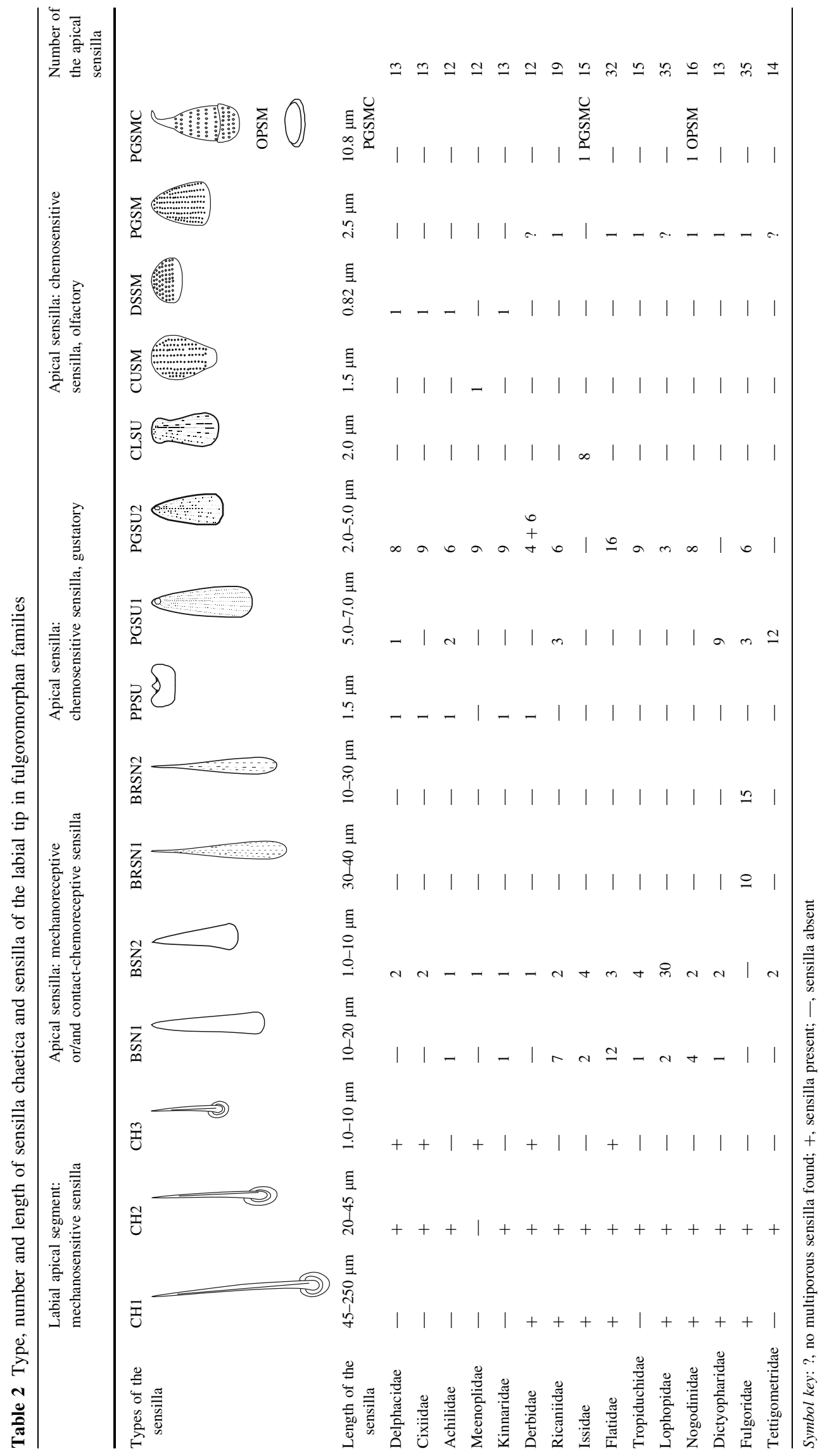



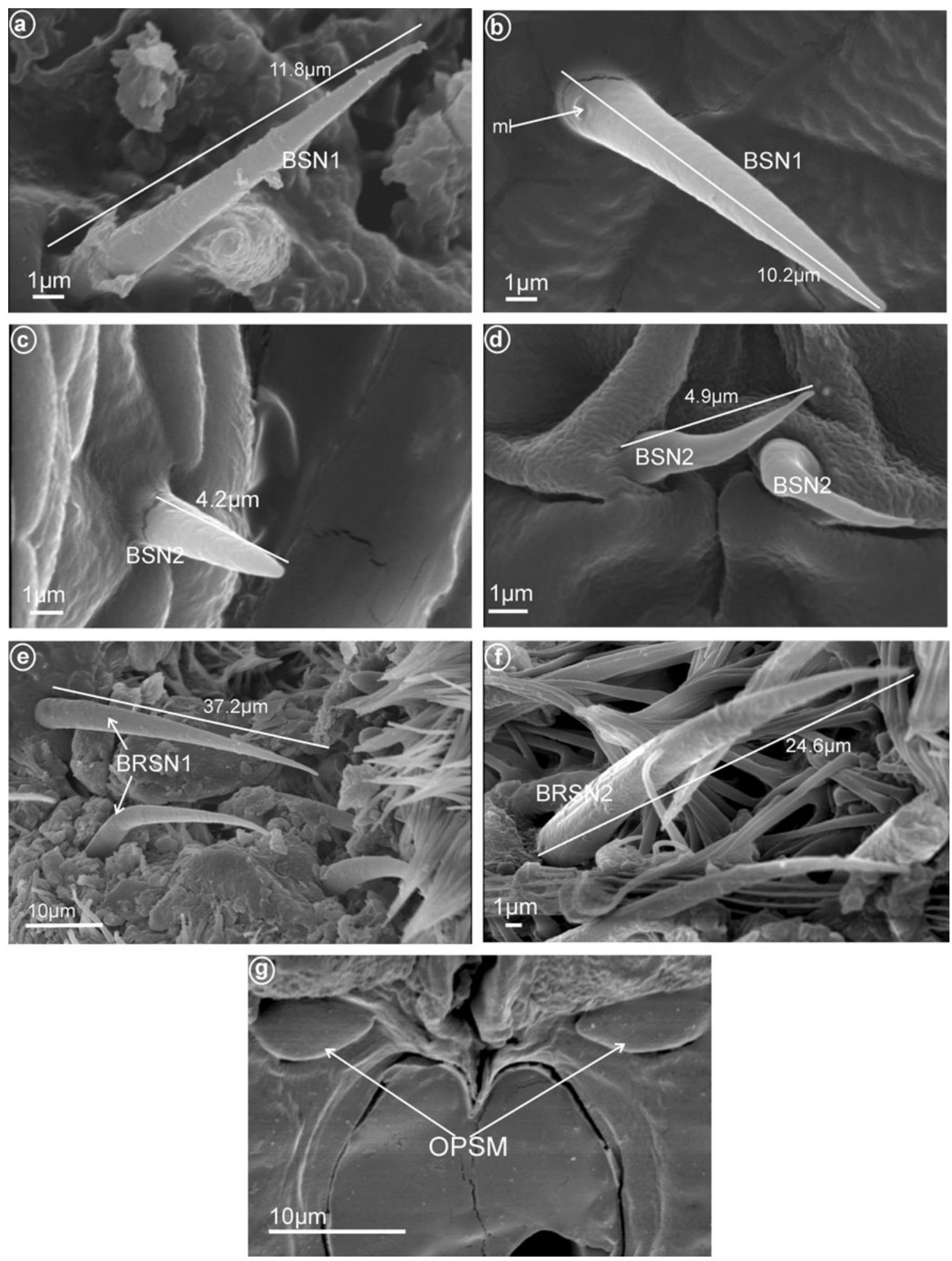

Fig. 1 Types and size of the apical sensilla of Fulgoromorpha. a, b BSN1 sensillum basiconicum. c, d BSN2 sensilla basiconica. e BRSN1 bristle-like sensilla. f BRSN2 bristle-like sensillum. g OPSM oval plate sensilla

$L=2.1 \mu \mathrm{m}$ ), Achilidae (Fig. 7d, sensillum no. 11), Meenoplidae Fig. 8c, d, sensillum no. 11, $L=2.6 \mu \mathrm{m}$ ), Kinnaridae (Fig. 9e, sensillum no. 12, $L=2.09 \mu \mathrm{m}$ ),
Derbidae (Fig. 10b, g, sensillum no. 12, $L=4.5 \mu \mathrm{m}$ ), Ricaniidae (Fig. 11d, sensilla no. 17-19, $L=2.9 \mu \mathrm{m}$, $L=3.1 \mu \mathrm{m}$ ), Issidae (Fig. 12b-d, sensilla no. 10-13, 

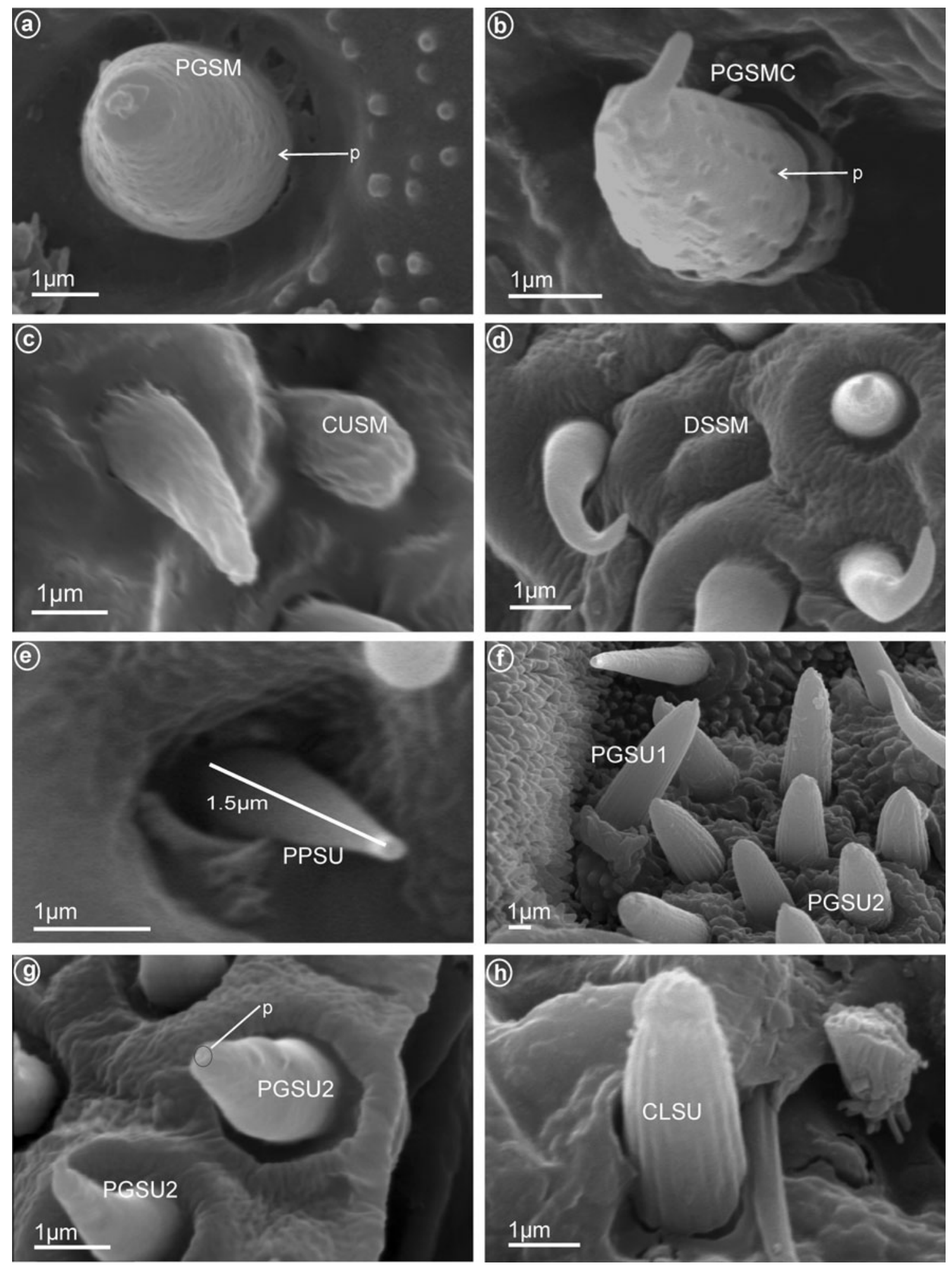

Fig. 2 Types of the apical chemosensilla of Fulgoromorpha. a PGSM peg sensillum. b PGSMC peg sensillum, complex. c CUSM cupolashaped sensillum. d DSSM dome-shaped sensillum. e PPSU peg-in-

pit sensillum. f PGSU1 peg sensillum. g PGSU2 peg sensillum. h CLSU clavate sensillum, p pore

$L=5.1 \mu \mathrm{m}, \quad L=7.2 \mu \mathrm{m}$ ), Flatidae (Fig. 13d, $L=1.1 \mu \mathrm{m}$ ), Tropiduchidae (Fig. 14c, d, g, sensilla no. $2,3,13,15, L=4.1 \mu \mathrm{m}$ ), Lophopidae (Fig. $15 \mathrm{c}$, g,

sensilla no. $1-30, L=3.7 \mu \mathrm{m}$ ), Nogodinidae (Fig. 16g, h, sensilla no. $13,14, L=2.7 \mu \mathrm{m})$, Dictyopharidae (Fig. 17d, g, h, sensilla no. 11, 13, $L=5.8 \mu \mathrm{m}$ ) and 

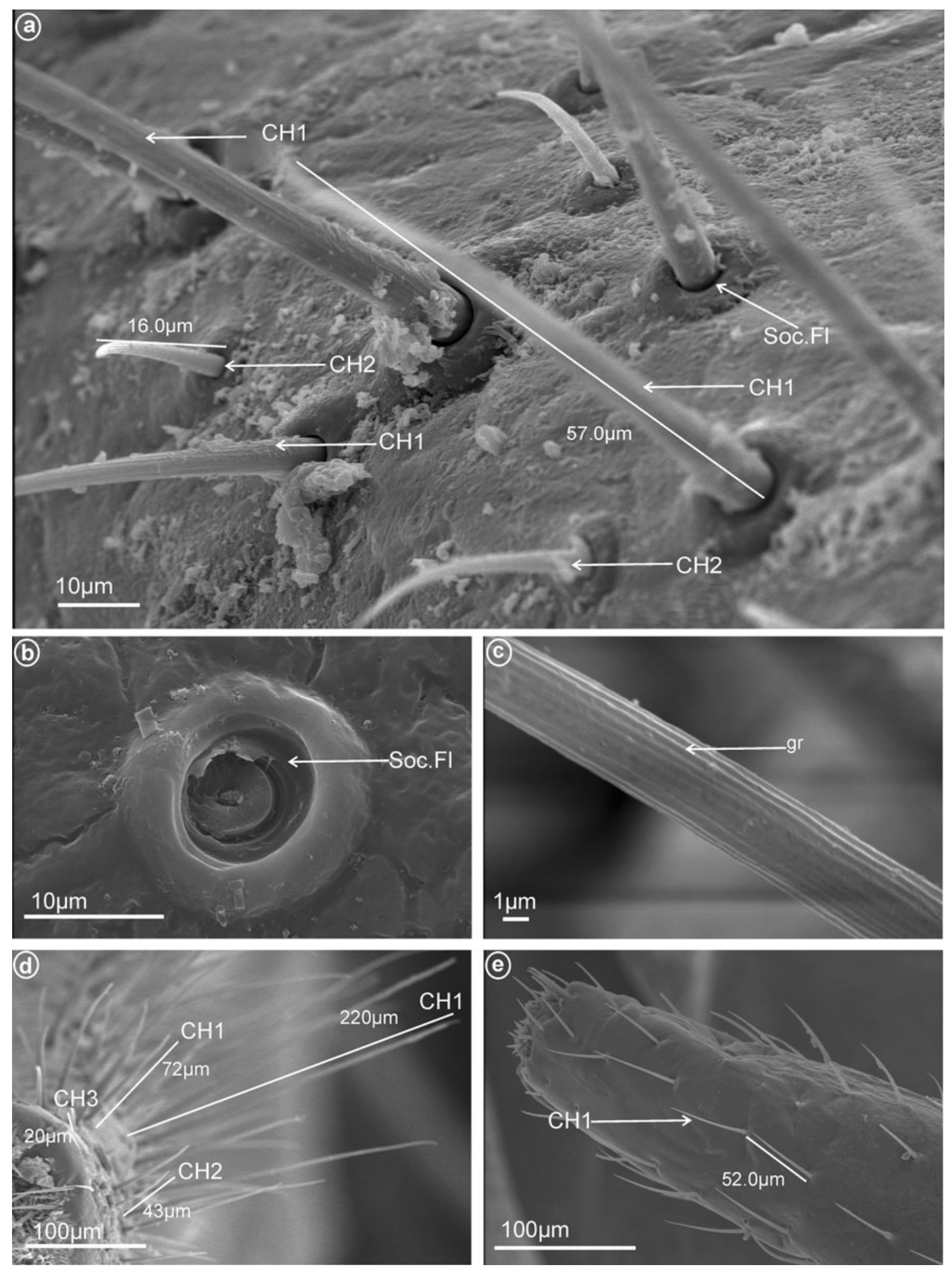

Fig. 3 Types of the mechanosensilla of fulgoromorphan families. a $\mathrm{CH} 1$ sensillum chaeticum, $\mathrm{CH} 2$ sensillum chaeticum. b Soc.Fl

sensillum chaeticum, sensilla $\mathrm{CH} 1, \mathrm{CH} 2, \mathrm{CH} 3$ densely arranged. flexible sockets. $\mathbf{c}$ Gr grooved surface of sensillum chaeticum. d CH3 

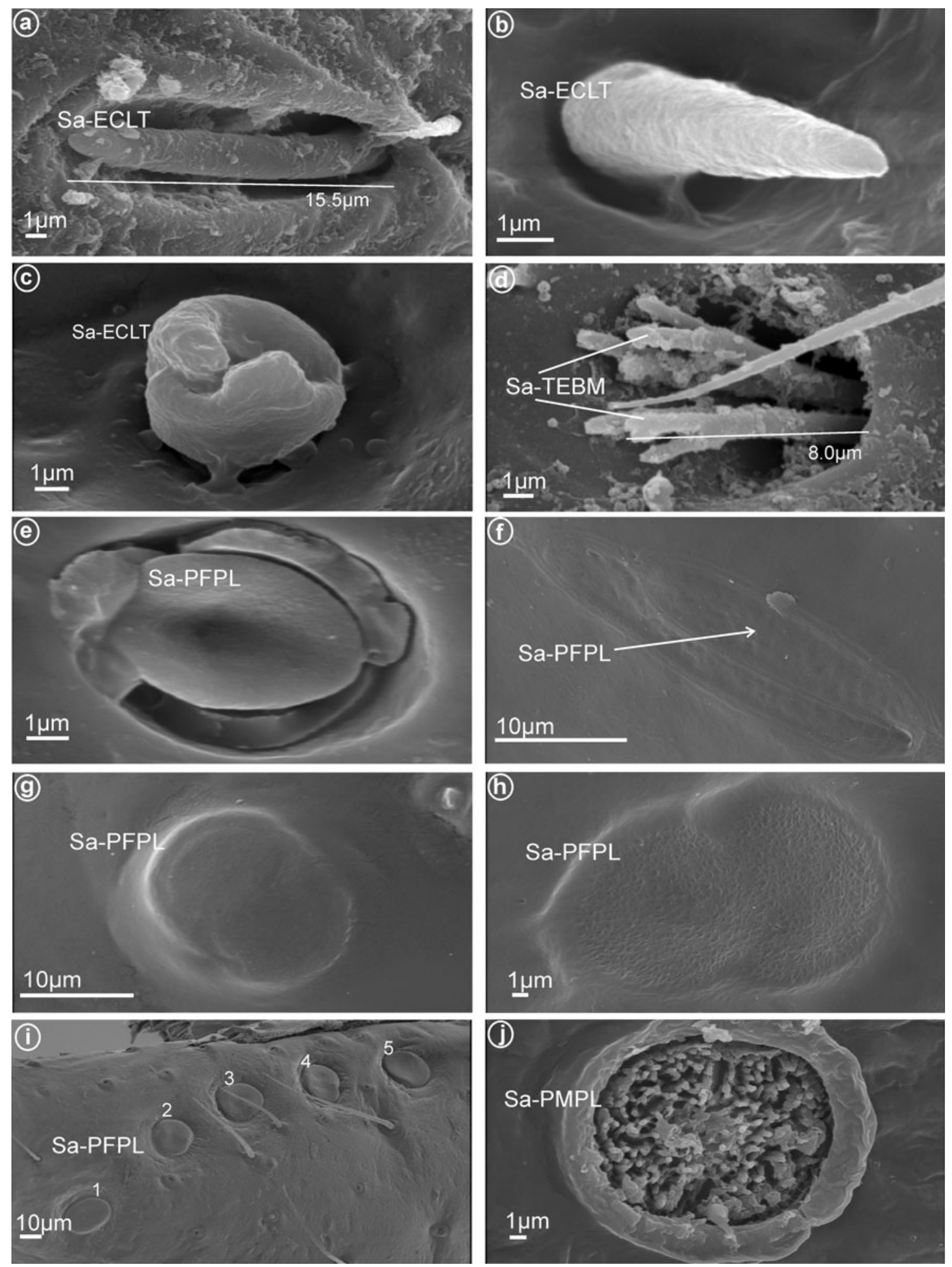

Fig. 4 Shapes of the subapical, multiporous labial sensilla in the fulgoromorphan families. a Sa-ECLT elevated, cone-like to tubular sensillum (Cixiidae). b Sa-ECLT elevated, cone-like to tubular sensillum (Meenoplidae). c Sa-ECLT elevated, cone-like to tubular sensillum (Lophopidae). d Sa-TEBM tubular, branched, multilobated sensillum (Delphacidae). e Sa-PFPL placoid flattened sensillum

(Achilidae). f Sa-PFPL placoid flattened sensillum (Dictyopharidae). g Sa-PFPL placoid flattened sensillum (Tropiduchidae). h Sa-PFPL placoid flattened sensillum (Ricaniidae). i Sa-PFPL placoid flattened sensilla (no. 1-5) (Nogodinidae). j Sa-PMPL placoid, multilobated, sensillum with numerous minute lobes (Flatidae) 

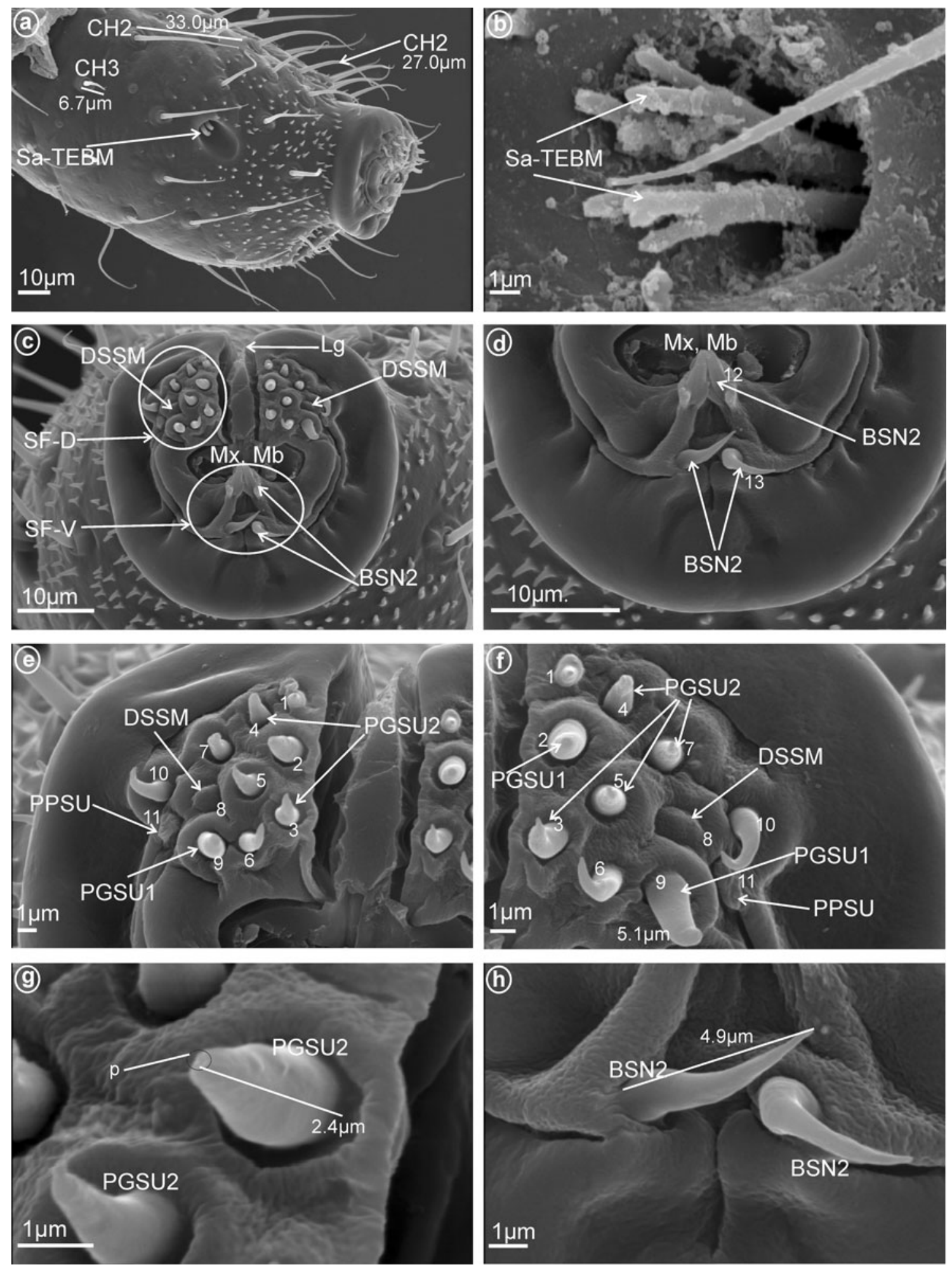

Fig. 5 Types and arrangement of the labial sensilla of Peregrinus maidis (Delphacidae). a $\mathrm{CH} 2, \mathrm{CH} 3, \mathrm{Sa}-\mathrm{TEBM}$ in lateral view. b SaTEBM (in enlargement). c SF-D with marked DSSM, SF-V with marked BSN2, Mx, Md. d Ventral sensory field with BSN2 (sensilla no. 12,13 ). e Right side of the labial tip (SF-D): DSSM (sensillum no.

8), PPSU (sensillum no. 11), PGSU1 (sensilla no. 2, 9) and PGSU2 (sensilla no. 3-5, 7 and no. 1, 6, 10). f Left side of the labial tip, sensilla placed symmetrically with respect to the right. $\mathbf{g}$ Length of the PGSU2, p pore. h Length of the BSN2 

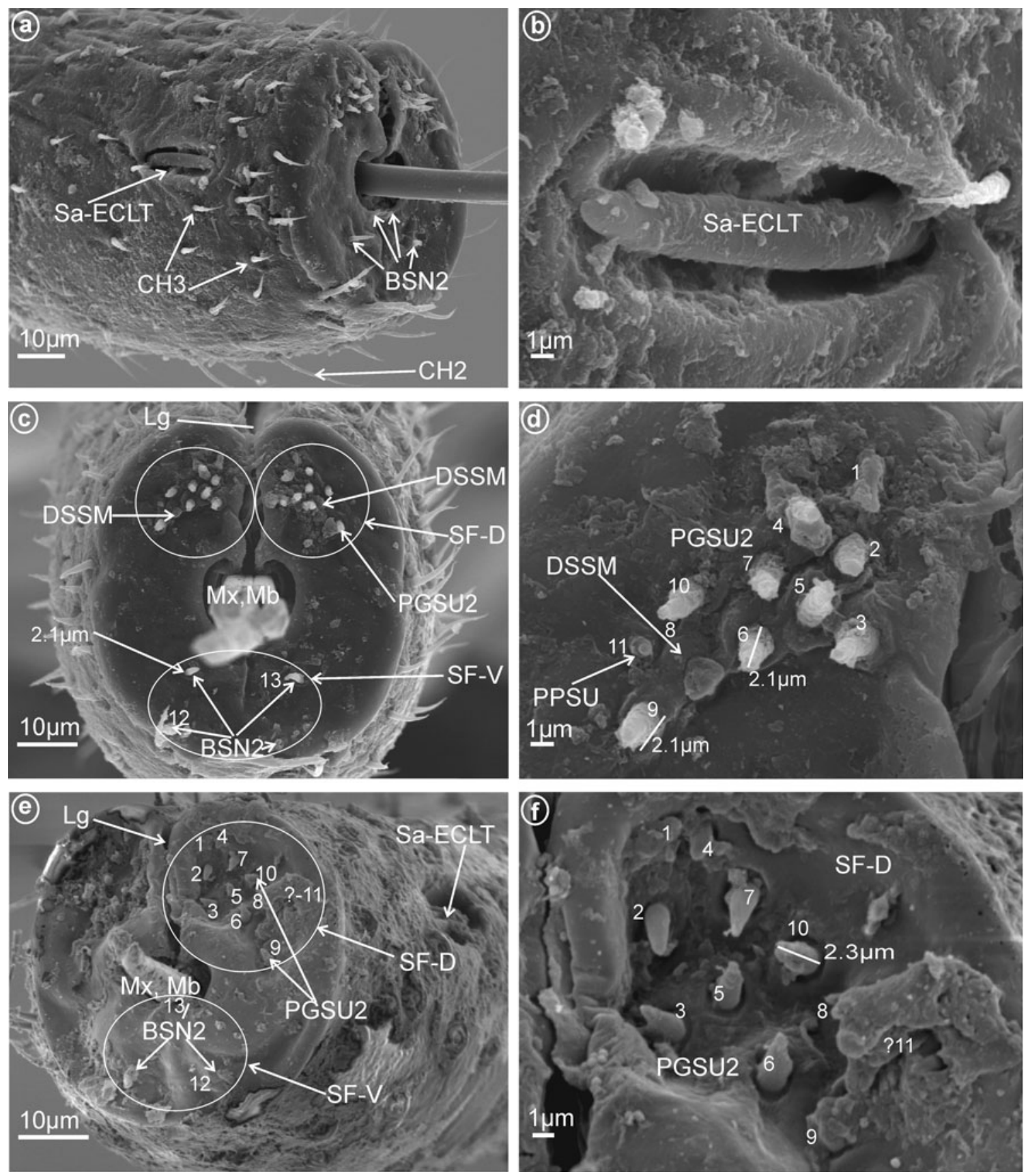

Fig. 6 Types and arrangement of the labial sensilla of Myndus taffini a-d (Cixiidae: Cixiinae: Oecleini) and e-f Brixidia boukokoensis (Cixiidae: Brixidiinae: Brixiidini), a BSN2, CH2, CH3, Sa-ECLT in lateral view. b Sa-ECLT (in enlargement). c SF-D with visible DSSM and PGSU2, SF-V with visible BSN2 (sensilla no. 12, 13), Mx, Md,

Tettigometridae (Fig. 19a, c, sensilla no. 13, 14, $L=6.8 \mu \mathrm{m})$.

- Short $(20-30 \mu \mathrm{m})$ and large $(30-40 \mu \mathrm{m})$ bristle-like sensilla, nonporous (BRSN1, Fig. 1e-f). These sensilla were only found in Fulgoridae (Fig. 18c-g, sensilla no. 11-35).

Lg. d PGSU2 (sensilla no. 1-7, 9, 10), PPSU (sensillum no. 11), DSSM (sensillum no. 8). e SF-D with PGSU2, PPSU (probably sensillum no. 11?), SF-V with visible BSN2 (sensilla no. 12, 13), Mx, Md, Lg. f Length of the PGSU2 (sensilla no. 1-7, 9, 10), PPSU (sensillum no. 11), DSSM (probably sensillum no. 8)

Chemoreceptive MP sensilla: olfactory sensilla at the tip of labium

Olfactory sensilla are of various shapes and sizes and pierced by numerous pores. According to Altner and Prillinger (1980), these are wall-pore sensilla or multiporous 

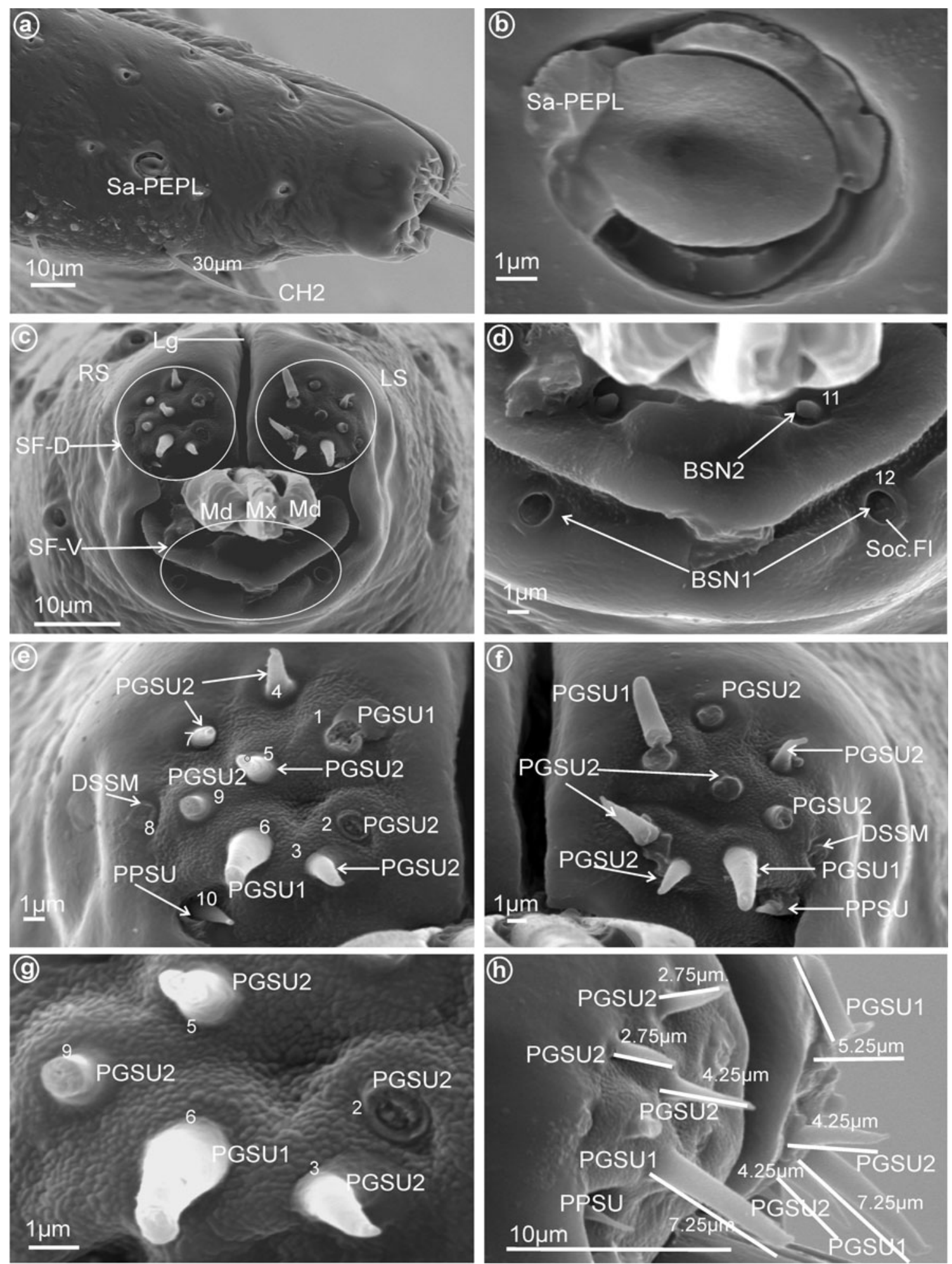

Fig. 7 Types and arrangement of the labial sensilla of Ballomarius kawandanus (Achilidae). a CH2, Sa-PFPL in lateral view. b Sa-PFPL (in enlargement). c Lg, SF-D and SF-V, Mx, Md in front view. d Ventral sensory field with BSN1 (sensillum no. 12) and BSN2 (sensillum no. 11), Soc.Fl. e Right side of the labial tip (SF-

D):PGSU1 (sensilla no. 1, 6), PGSU2 (sensilla no. 2-5, 7, 9), DSSM (sensillum no. 8) and PPSU (sensillum coeloconicum no. 10). f Left side of the labial tip, sensilla are arranged in the same way as for the right side. $\mathbf{g}$ PGSU2 and PGSU1 (in enlargement). $\mathbf{h}$ Length $(\mu \mathrm{m})$ of the PGSU1 and PGSU2 sensilla 

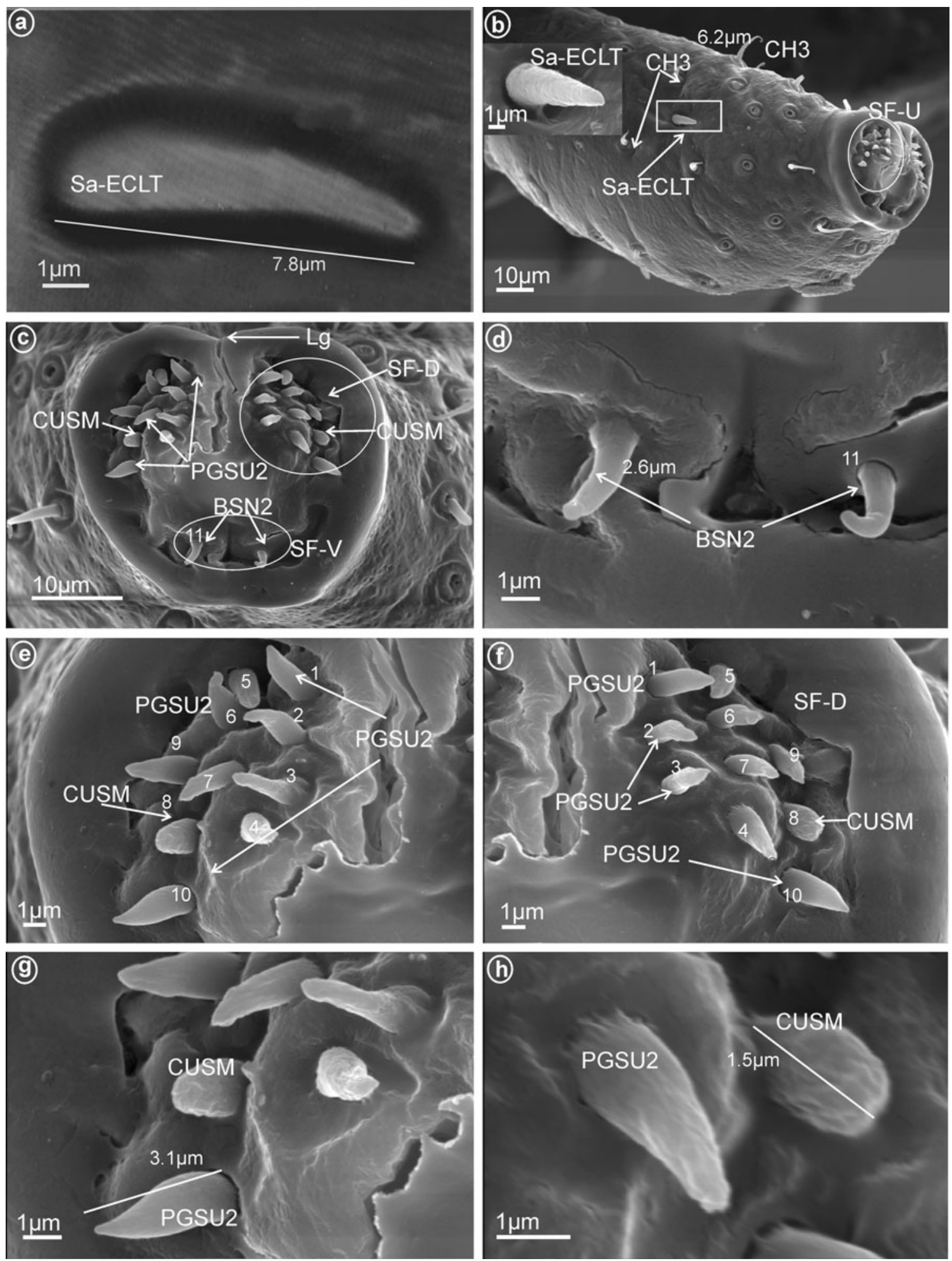

Fig. 8 Types and arrangement of the labial sensilla of Meenoplidae. a Kermesia immaculata, length of the Sa-ECLT. b-h Nisia nervosa, b CH3, Sa-ECLT, sensilla in lateral view. c SF-D with PGSU2 and CUSM, SF-V with BSN2 (sensillum no. 11). d Ventral sensory field

with BSN2 (length of the BSN2). e, f Right and left side of the labial tip, dorsal sensory fields with PGSU2 (sensilla no. 1-7, 9,10) and CUSM (sensillum no. 8). $\mathbf{g}$, h Length $(\mu \mathrm{m})$ of the PGSU2 and of the CUSM 

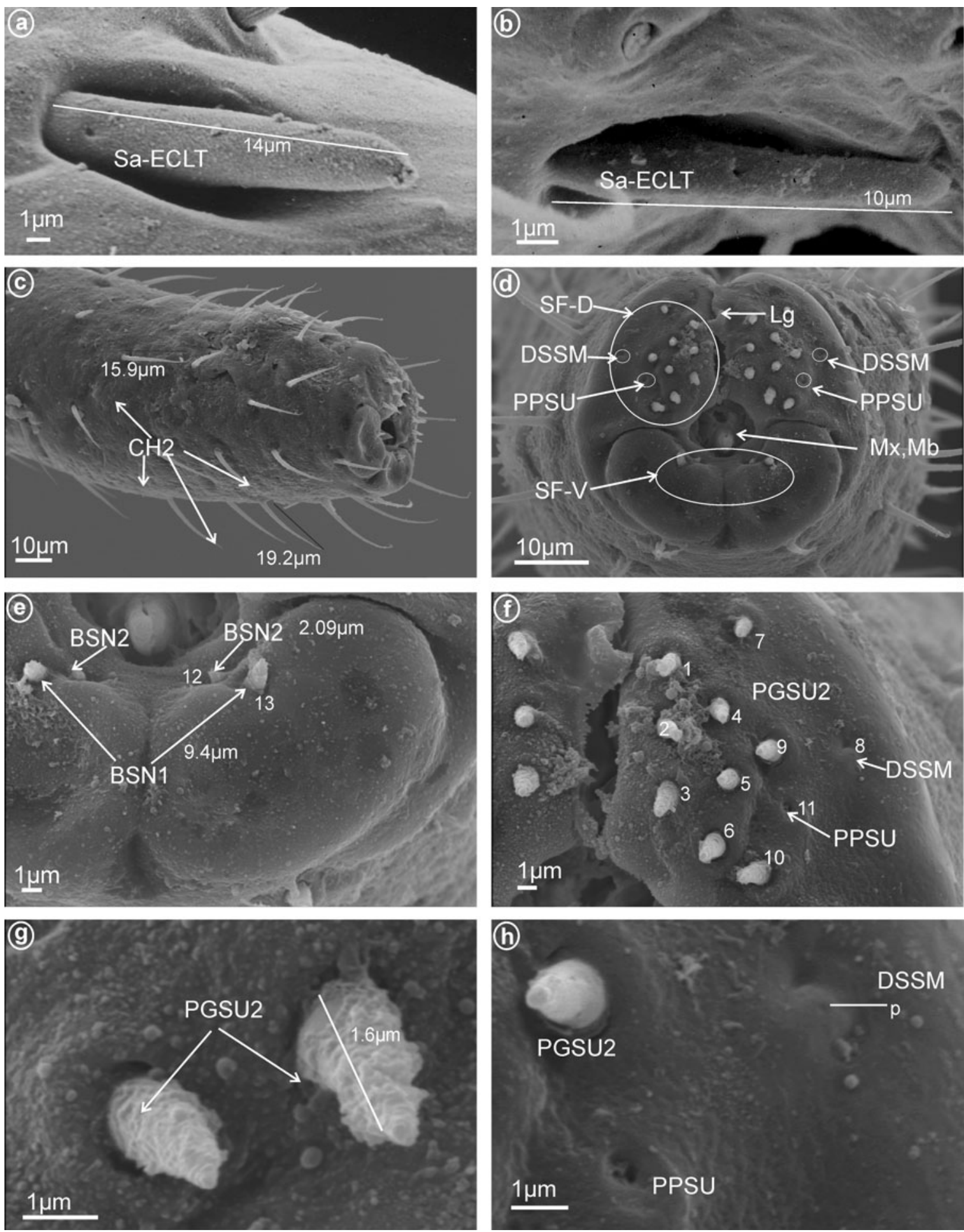

Fig. 9 Types and arrangement of the labial sensilla of Kinnaridae. a Southia capnorhina, length of the Sa-ECLT. b Atopocixius major, length of the Sa-ECLT. c-h Nesomircixia insularis, c length of the $\mathrm{CH} 2$, sensilla spaced in series, evenly. d SF-D with visible DSSM and PPSU, SF-V is marked, Mx, Md. e Ventral sensory field with BSN1

(sensillum no. 13, length $9.4 \mu \mathrm{m}$ ) and BSN2 (sensillum no. 12, length $2.09 \mu \mathrm{m}$ ). f Left side of the labial tip: PGSU2 (sensilla no. 1-7, 9, 10), DSSM (sensillum no. 8) and PPSU (sensillum no. 11). g Length of the PGSU2. h Distribution of the DSSM and PPSU (sensillum coeloconicum), p-pores 

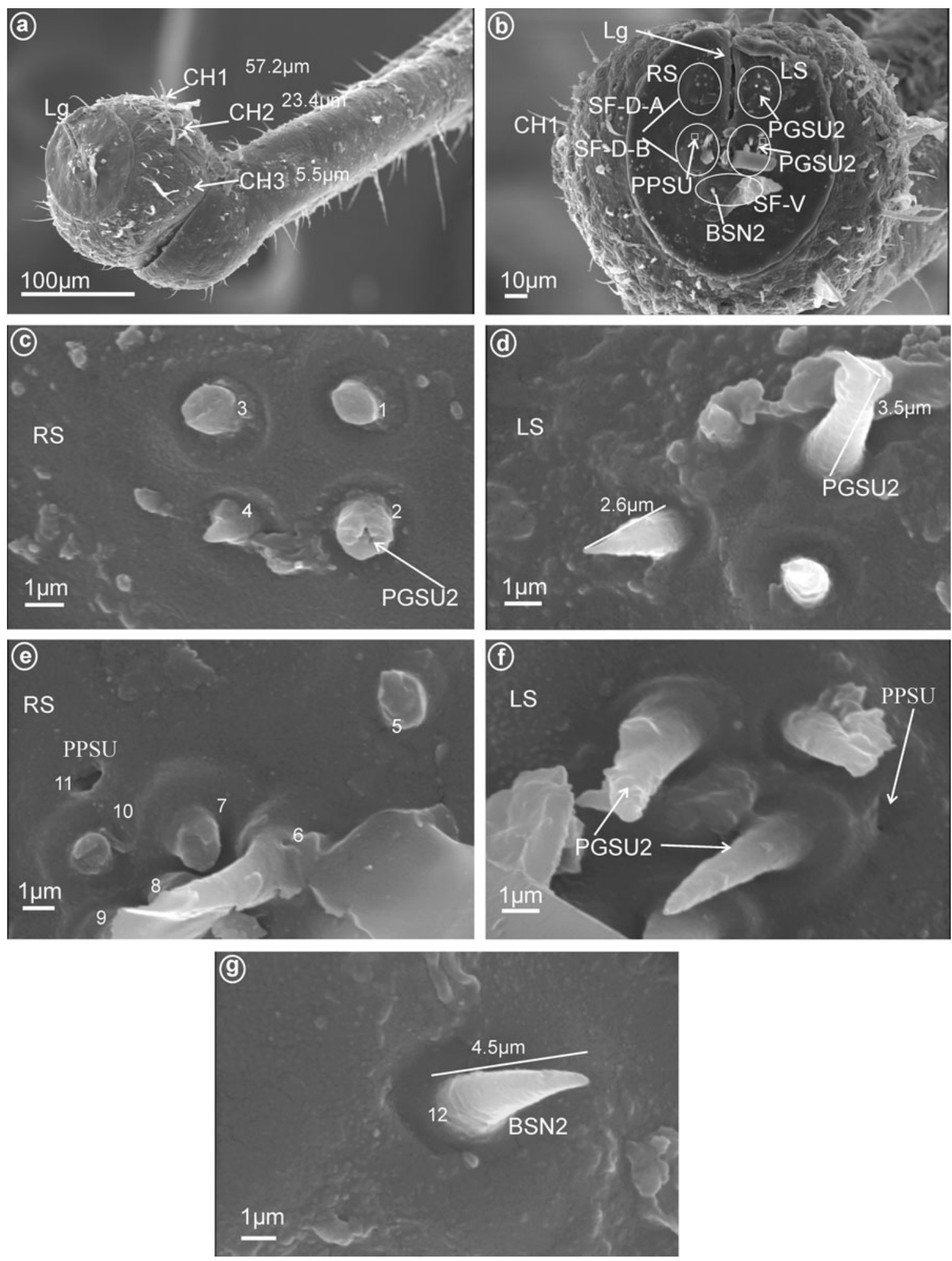

Fig. 10 Types and arrangement of the labial sensilla of Proutista fritillaris (Derbidae). a Length of the $\mathrm{CH} 1, \mathrm{CH} 2$ and $\mathrm{CH} 3$. b SF-D-A (there are four PGSU2), SF-D-B (there are six PGSU2 and one PPSU), SF-V with BSN2. c Right side (RS) of the SF-D-A with
PGSU2 (sensilla no. 1-4). d Left side (LS) of the SF-D-A, length of the PGSU2 sensilla. (e) RS, dorsal sensory field B, distribution of the PPSU (sensillum no. 11) and PGSU2 (sensilla no. 5-10). f PGSU2 and PPSU (in enlargement). $\mathbf{g}$ Length of the BSN2 (sensillum no. 12) 

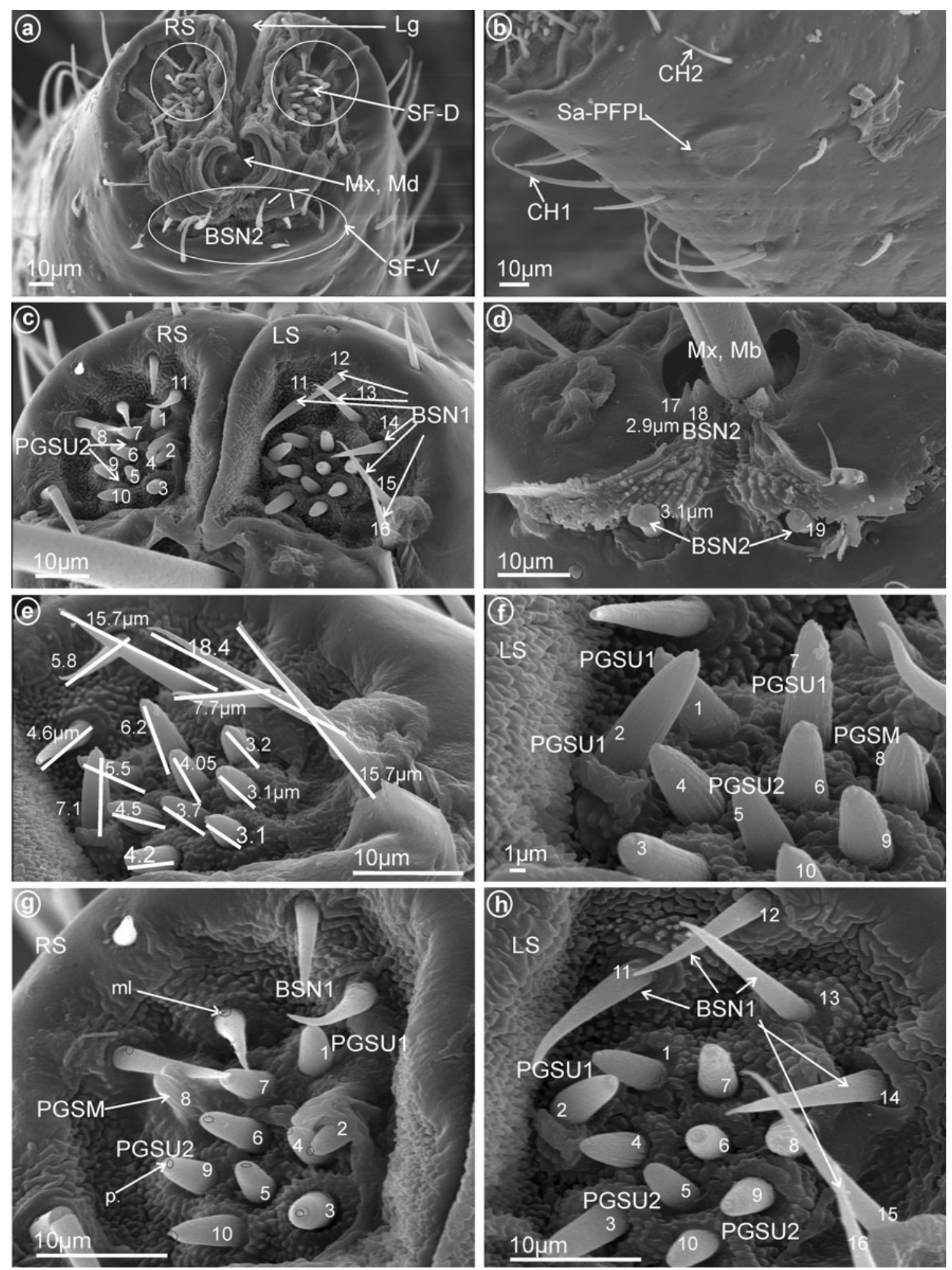

Fig. 11 Types and arrangement of the labial sensilla of Pochazia fuscata (Ricaniidae). a Labial tip, in front view: Lg, SF-D, SF-V with BSN, Mx, Md, RS right side of the tip. b Distribution of the sensilla $\mathrm{CH} 1, \mathrm{CH} 2$ and Sa-PFPL. c Dorsal sensory fields: PGSU2 (sensilla no. 3-6, 9, 10) and BSN1 (sensilla no. 11-16). d Ventral sensory field

with BSN2 (sensilla no. 17-19). e Length of individual sensilla. f Dorsal sensory field with PGSM (sensillum no. 8), PGSU1 (sensilla no. 1, 2, 7) and PGSU2 (sensilla no. 3-6, 9, 10). g, h Detailed view: BSN1, PGSU1, PGSU2 and PGSM on the right (RS) and the left (LS) side of the dorsal sensory fields, $\mathrm{p}$ pore, $\mathrm{ml}$ molting pore 

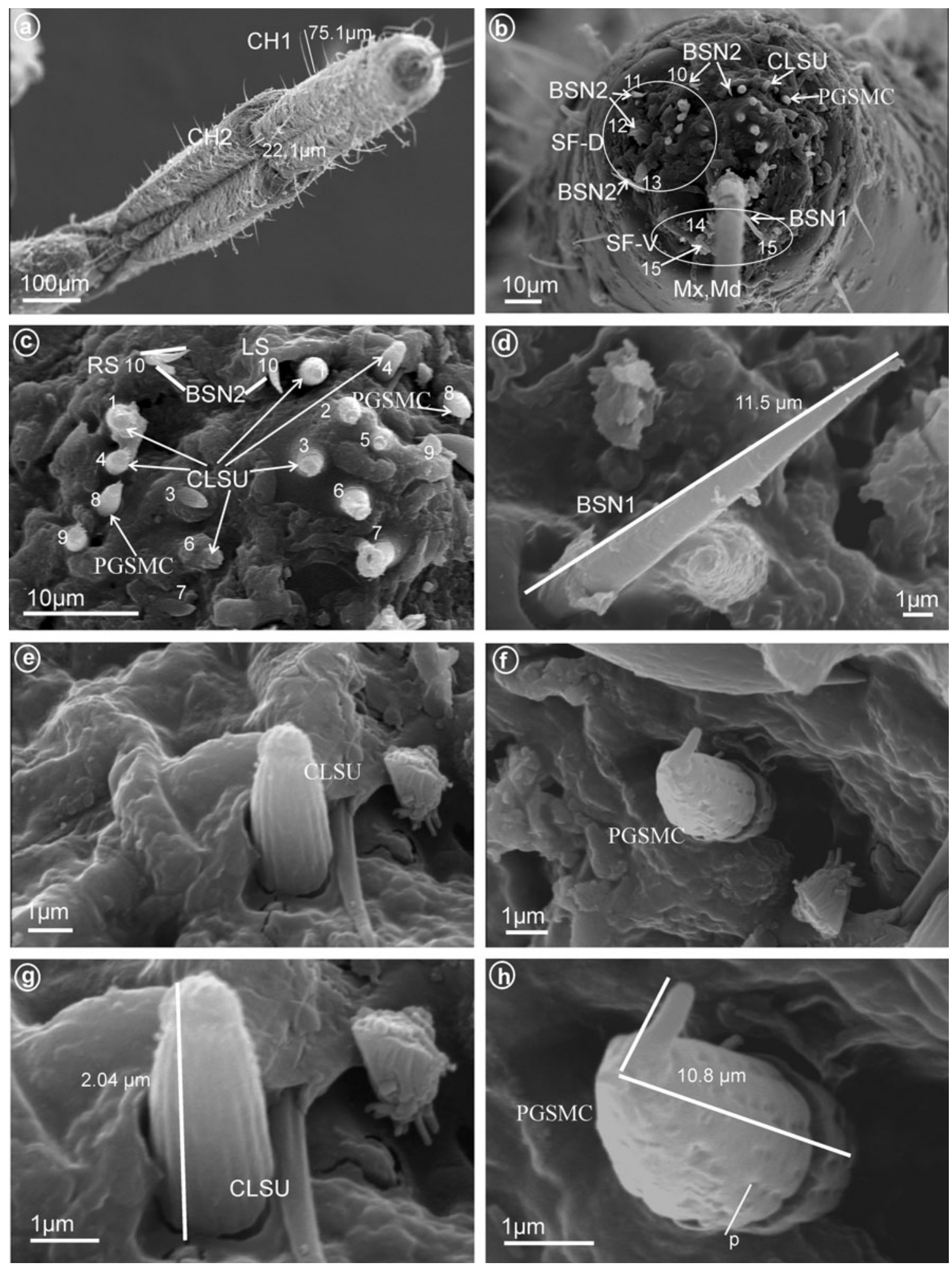

Fig. 12 Types and arrangement of the labial sensilla of Trienopa paradoxa (Issidae). a Length of the $\mathrm{CH} 1$ and $\mathrm{CH} 2$. b Front view on: SF-D with sensilla BSN2 (no. 10-13), CLSU and PGSMC, SF-V with

CLSU (sensilla no. 1-7, 9) and PGSMC (sensillum no. 8). d Length of the BSN1. e Shape of the CLSU. f Shape of the PGSMC. $\mathbf{g}$ Length of the CLSU. h Length of the PGSMC, p-pores are visible 

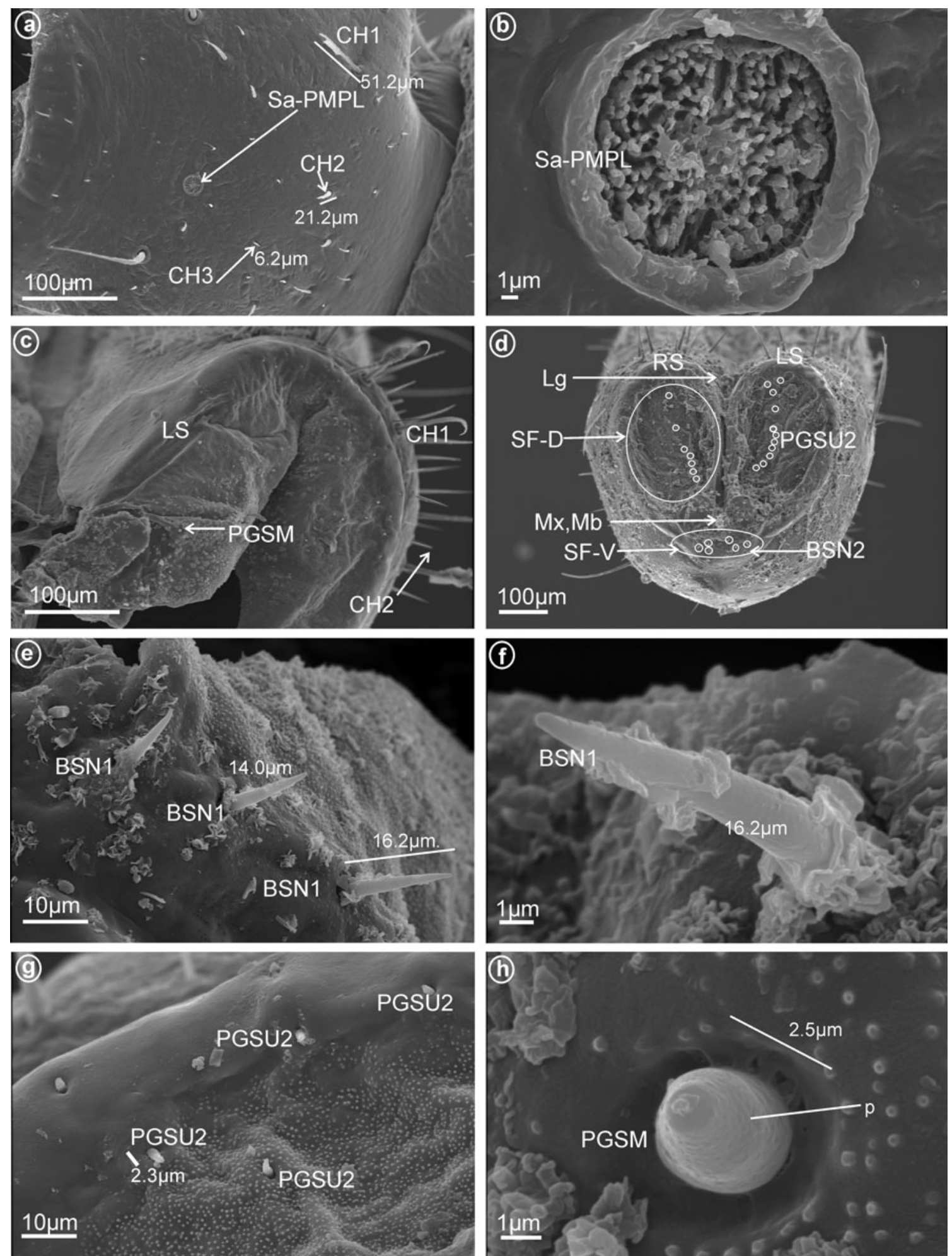

Fig. 13 Types and arrangement of the labial sensilla of Flatida sp. (Flatidae). a Length of the $\mathrm{CH} 2, \mathrm{CH} 3$ and location of the Sa-PMPL.

marked on dorsal sensory field (SF-D), SF-V with the BSN2, Mx, Md. e Length and distribution of the BSN1 in the dorsal sensory field. f Detailed view on surface of the BSN1. g Distribution and size of the d Front view on labial tip: right (RS) and left (LS) tip, Lg, PGSU2 are

PGSU2. h Detailed view on surface of the PGSM, p-pores are visible 

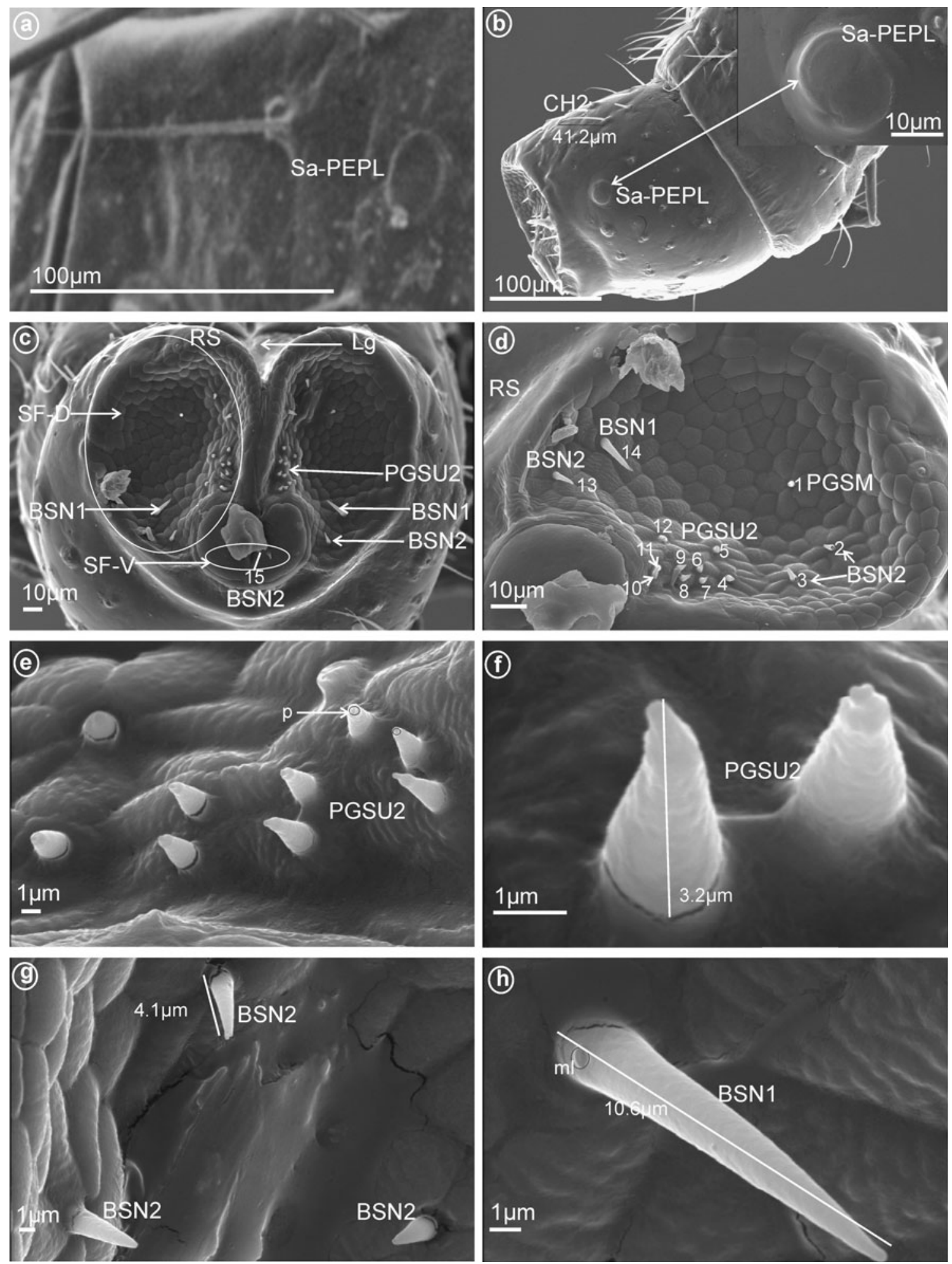

Fig. 14 Types and arrangement of the labial sensilla of Tropiduchidae. a Tropiduchus arisba, Sa-PEPL, in lateral view. b-h Numicia hulstaerti. b Sub-apical location of the Sa-PEPL, length of the CH2. c SF-D with sensilla BSN1, BSN2 and PGSU2, SF-V with the BSN2 (sensillum no. 15). d Detailed view on right side (RS) of the dorsal

sensory field: PGSM (sensillum no. 1), BSN2 (sensilla no. 2, 3, 13), PGSU2 (sensilla no. 4-12) and BSN1(sensillum no. 14). e Distribution of the PGSU2 in the dorsal sensory field, p pore. $\mathbf{f}$ Length of the PGSU2. $\mathbf{g}, \mathbf{h}$ Length of the BSN2 and BSN1, a molting pore $(\mathrm{ml})$ is visible 

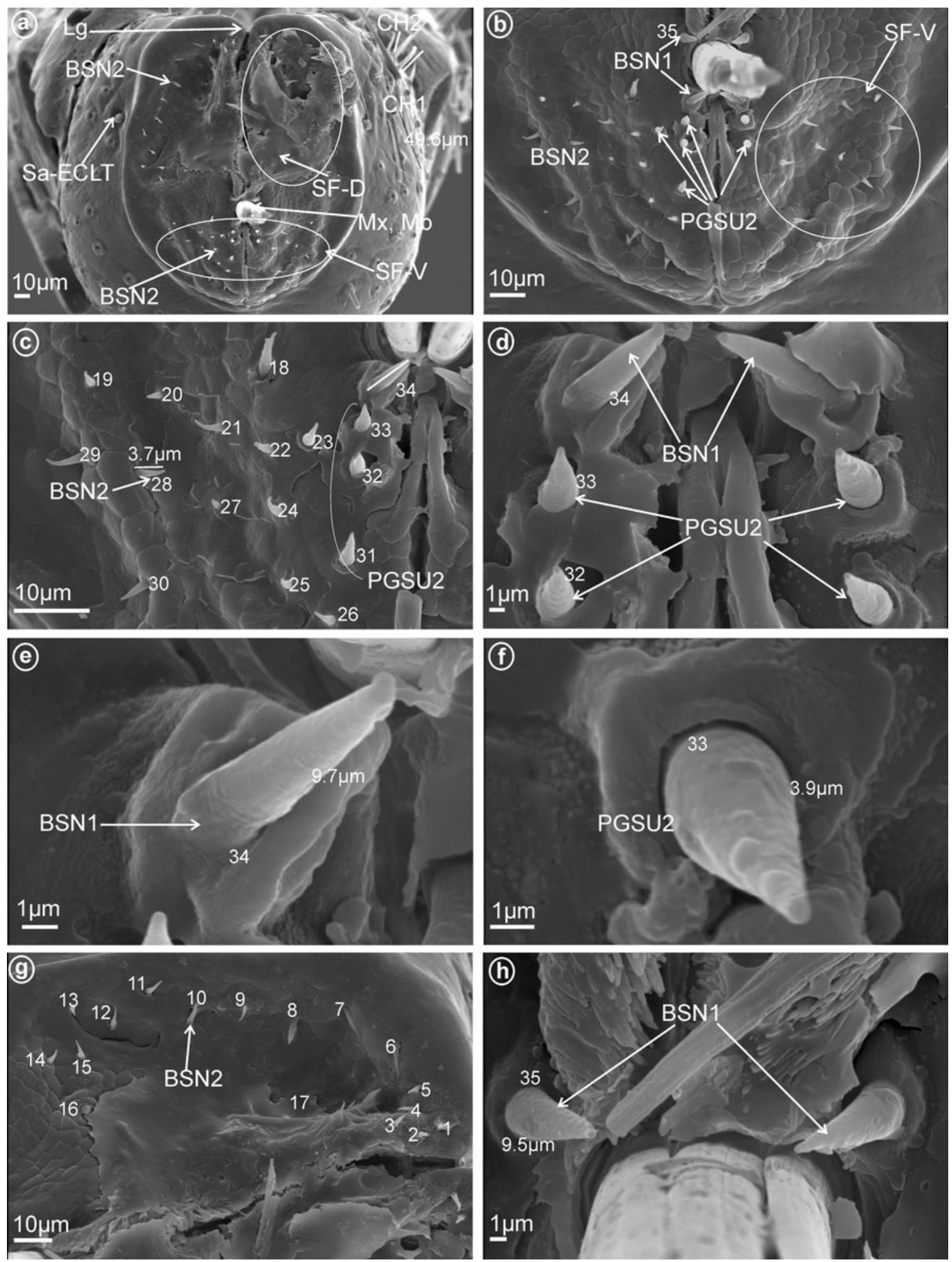

Fig. 15 Types and arrangement of the labial sensilla of Lophops africana (Lophopidae). a Length of the $\mathrm{CH} 1, \mathrm{CH} 2$ and location of the Sa-ECLT, Lg, SF-D, SF-V, Mx, Md. b Ventral sensory field with visible BSN1, BSN2 and PGSU2. c, d Distribution of the sensilla in the ventral sensory field, BSN2 (sensilla no. 18-30), BSN1 (sensilla

no. 34) and PGSU2 (sensilla no. 31-33). e Length of the BSN1 (sensillum no. 34). f Length of the PGSU2 (sensillum no. 33). g Numbers and location of BSN2 in the dorsal sensory field (sensilla no. 1-16). h BSN1 (sensillum no. 35) localized above the maxilla and mandibles 

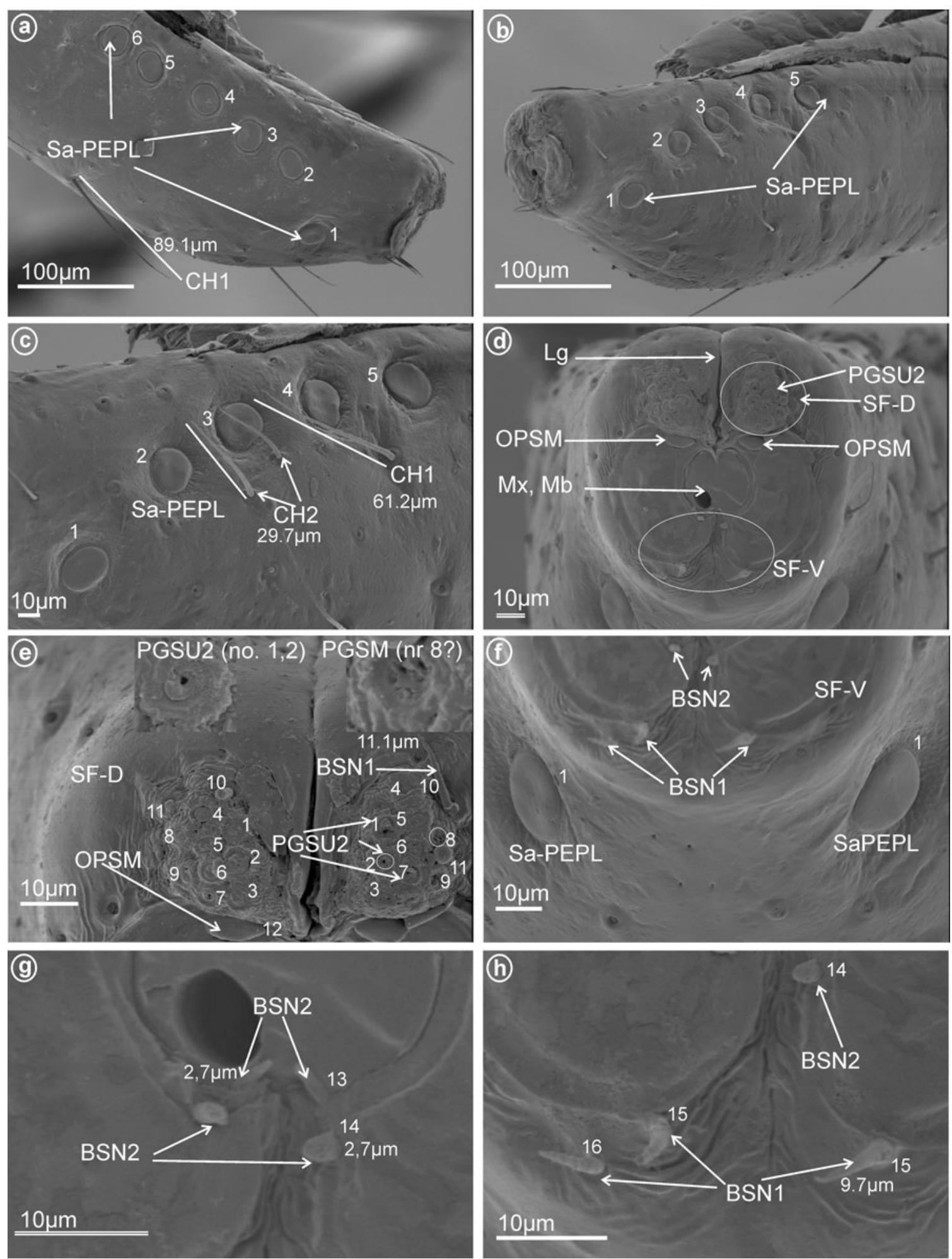

Fig. 16 Types and arrangement of the labial sensilla of Nogodina reticulata (Nogodinidae). a Sa-PFPL (sensilla no. 1-6 on the right side). b Sa-PFPL (sensilla no. 1-5 on the left side). c Location of the Sa-PFPL and length of the $\mathrm{CH} 2$ and $\mathrm{CH} 1$. d Front view of the labial tip: PGSU2, Lg, SF-D, SF-V, Mx, Md, OPSM placed slightly below of the dorsal sensory field. e Dorsal sensory field with BSN1 (sensilla

no. 10, 11), PGSM (sensillum no. 8 probably, there are five apertures at the base of this sensillum), PGSU2 (sensilla no. 1-7, 9, one aperture at the base in the case of these sensilla) and OPSM placed below the sensory field (sensillum no. 12). f-h Distribution of the sensilla in the ventral sensory field, BSN2 (sensilla no. 13, 14) and BSN1 (sensilla no. 15, 16) 

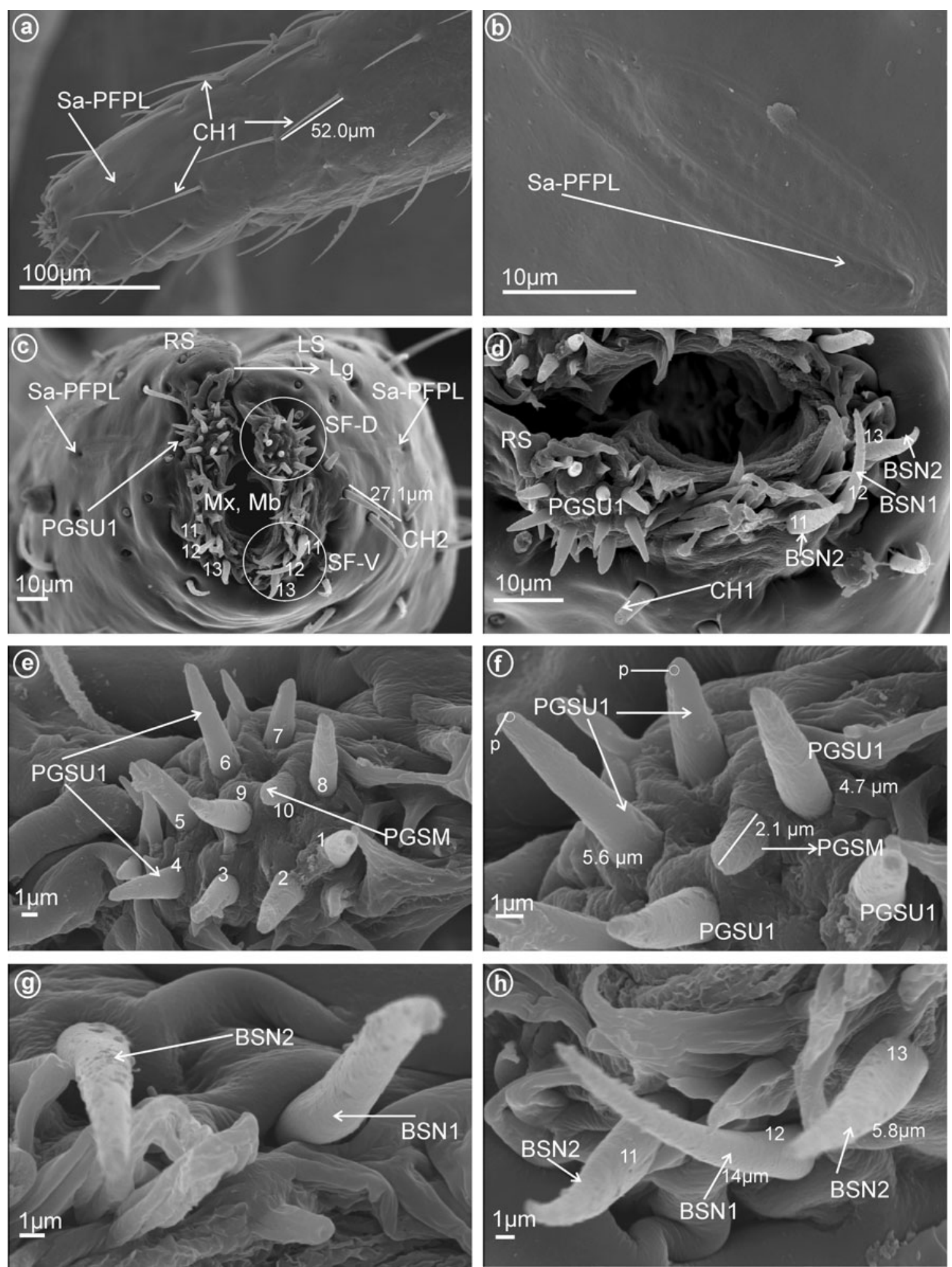

Fig. 17 Types and arrangement of the labial sensilla of Afronersia dionacea (Dictyopharidae). a Length of the $\mathrm{CH} 1$, location of the SaPFPL. b Detailed view, Sa-PFPL sensillum, placoid flattened, multiporous. c Front view on the labial tip: Lg, SF-D, SF-V, Mx, $\mathrm{Md}$, right side (RS) and left side (LS) of the tip, length of the $\mathrm{CH} 2$. d The dorsal and ventral sensory field with PGSU1 sensilla, BSN1

and BSN2 (sensilla no. 11, 13). e, f Distribution and length of the sensilla in the dorsal sensory field, PGSU1 (sensilla no. 1-9), PGSM (sensillum no. 10), p pore. $\mathbf{g}$, h Distribution of the sensilla in the ventral sensory field BSN1 (sensillum no. 12) and BSN2 (sensilla no. $11,13)$ 

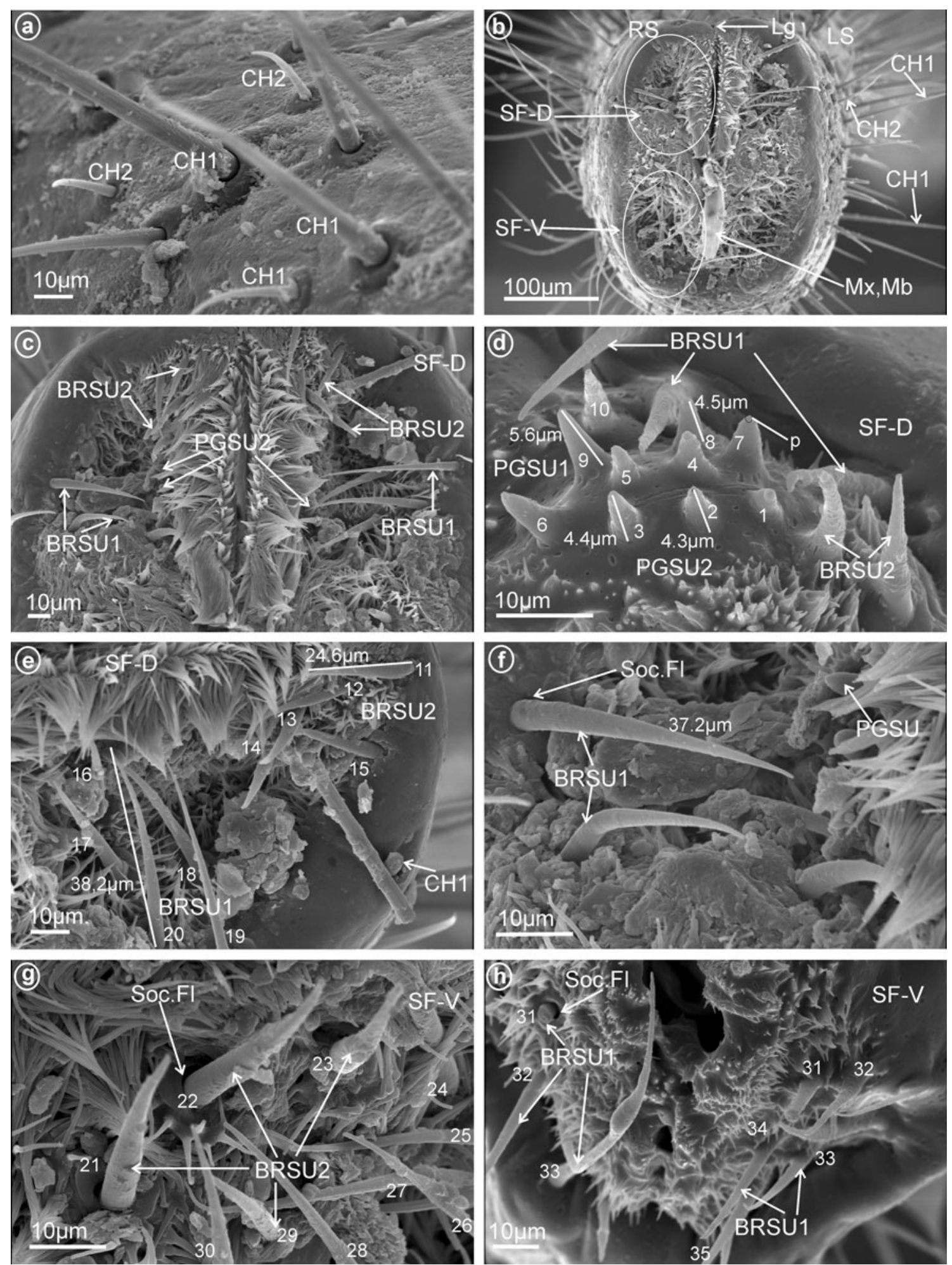

Fig. 18 Types and arrangement of the labial sensilla of Calyptoproctus sp. (Fulgoridae). a Length of the $\mathrm{CH} 1, \mathrm{CH} 2$. b Front view of the labial tip: Lg, SF-D, SF-V, Mx, Md, RS right side, LS left side of the tip. c The dorsal sensory field with BRSU1 and BRSU2. d The dorsal sensory field with PGSU2 (sensilla no. 1-6), PGSU1 (sensilla

no. 7-10). e Distribution and size of the sensilla on the dorsal sensory field, BRSU2 (sensilla no. 11-16) and BRSU1 (sensilla no. 17-20). f Length of the BRSU1. $\mathbf{g}, \mathbf{h}$ Distribution of the sensilla in the ventral sensory field: BRSU2 (sensilla no. 21-24) and BRSU1 (sensilla no. 25-35), Soc.Fl flexible socket 
sensilla as described by Zacharuk (1980). Five types of sensilla showing morphological characteristics connected with olfaction or olfacto-thermo reception are as follows:

- Oval plate sensilla, multiporous (OPSM, Fig. 1g). A pair of this type of sensillum were found only in Nogodinidae below the dorsal sensory field (Fig. 16d, e, sensillum no. 12).

- Peg sensilla, multiporous (PGSM, Fig. 2a). Coneshaped with round tip sensillum with length ranging between 2.0 and $4.5 \mu \mathrm{m}$ according to family. One pair of this type of sensillum was observed in Ricaniidae (Fig. 11f-h, sensillum no. 8, $L=3.2 \mu \mathrm{m}$ ), Flatidae (Fig. 13c, h, $L=2.5 \mu \mathrm{m}$ ), Tropiduchidae (Fig. 14d, sensillum no. 1), Nogodinidae (Fig. 16e, sensillum no. 8?-probably), Dictyopharidae (Fig. 17e, f, sensillum no. $10, L=2.1 \mu \mathrm{m}$ ) and Fulgoridae (Fig. 18d, sensillum no. $8, L=4.5 \mu \mathrm{m}$ ).

- Peg sensilla, multiporous, complex (PGSMC, Fig. 2b). This sensillum is divided into two parts by a furrow. Its length is $10.8 \mu \mathrm{m}$ (Fig. 12h), and its tip is strongly pointed (Fig. 12f, h). Only one pair of this type of sensillum was observed, in Issidae (Fig. 12c, sensillum no. 8).
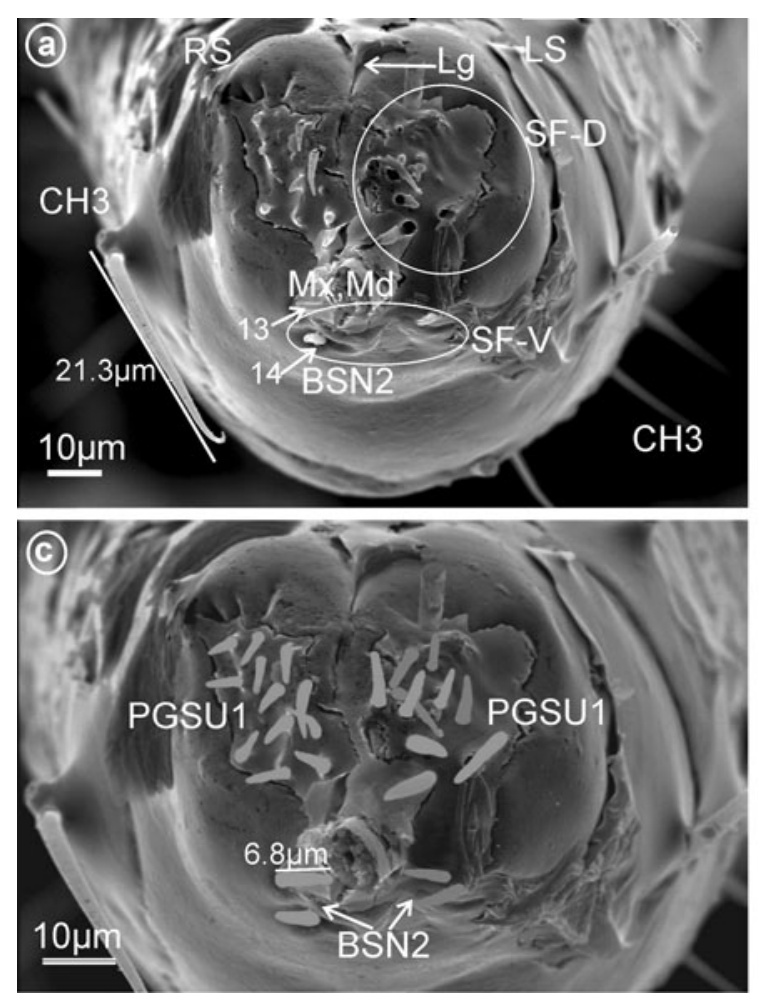

Fig. 19 Types and distribution of the labial sensilla of Tettigometridae. Tettigometra sulphurea, a Length of the $\mathrm{CH} 3$ and location of the BSN2 (sensilla no. 13, 14), right side (RS) and left side (SL) of the tip, Lg, SF-D, SF-V, Mx, Md. b Dorsal sensory field with PGSU1

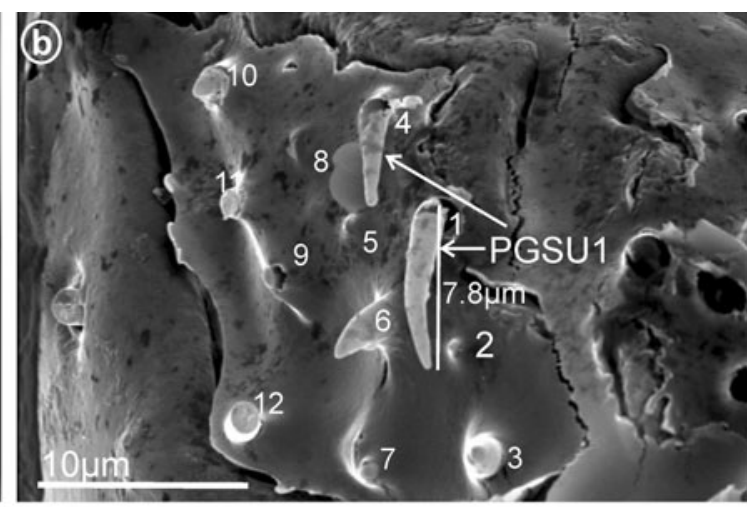

- Cupola-shaped sensilla, multiporous (CUSM, Fig. 2c). In this sensillum, the upper part is strongly enlarged relative to its base. The length of this sensillum is $1.5 \mu \mathrm{m}$ (Fig. 8h). One pair of this kind of sensillum appeared to be specific for Meenoplidae (Fig. 8c, e-h, sensillum no. 8).

- Dome-shaped sensilla, multiporous (DSSM, Fig. 2d). Short sensilla (above $0.82 \mu \mathrm{m}$ ) with tip strongly flattened distinctly multiporius. One pair of this type of sensillum was situated on the dorsal sensory field among peg sensilla in Delphacidae (Fig. 5c, e, f, sensillum no. 8), Cixiidae (Fig. 6c, d, sensillum no. 8), Achilidae (Fig. 7e, f, sensillum no. 8) and Kinnaridae (Fig. 9d, f, h, sensillum no. 8).

Chemoreceptive UP sensilla: gustatory sensilla at the tip of the labium

These gustatory sensilla are bristles, hairs, pegs or just elevations of the cuticle, or a single flat cuticular area, all with a single terminal pore (TP-sensilla, uniporous) (Altner and Prillinger 1980). Peg sensilla have their side walls usually smooth but some have longitudinal ridges. They are

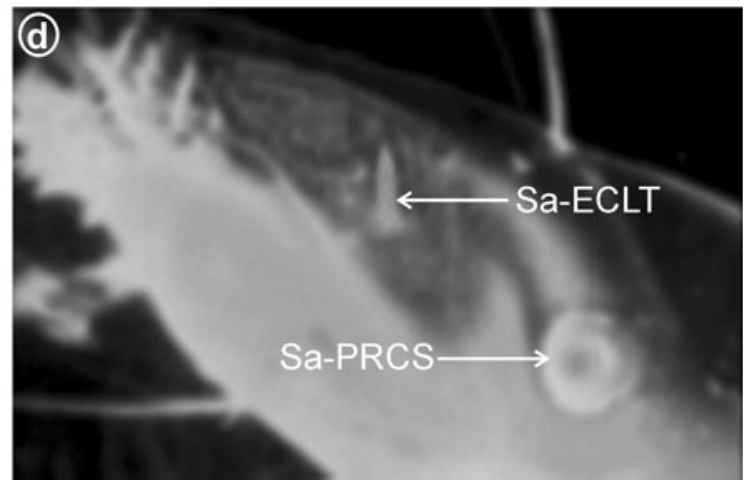

(sensilla no. 1-12). c Distribution of the PGSU1 and BSN2 sensilla on labial tip. d Euphyonarthex phyllostoma, Sa-ECLT elevated cone-like sensillum and Sa-PRCS placoid, rounded and convex sensillum 
divided into four types based on their length and shape of the tip as follows.

Pit peg sensilla, uniporous (PPSU, Fig. 2e = sensilla coeloconica) These are typical peg-in-pit sensilla; they do not have any articulation and are characterized externally by a round aperture. The peg is oriented toward the inside of the pit in such a way that it is positioned in an exactly perpendicular position with respect to the external opening of the pit. One pair of these sensilla was observed in representatives of Delphacidae (Fig. 5e, f, sensillum no. 11), Cixiidae (Fig. 6d, sensillum no. 11), Achilidae (Fig. 7e, f, h, sensillum no. $10, L=1.5 \mu \mathrm{m}$ ), Kinnaridae (Fig. 9d, f, h, sensillum no. 11) and Derbidae (Fig. 10b, e, f, sensillum no. 11).

Peg sensilla, uniporous (PGSU1, Fig. 2f) These coneshaped sensilla are long $(5.0-7.5 \mu \mathrm{m})$ with a rounded tip. This kind of the sensillum was found in Delphacidae (Fig. 5e, f, sensilla no. 2 and 9, $L=5.1 \mu \mathrm{m}$ ), Achilidae (Fig. 7e-h, sensilla no. 1 and $6, L=7.25 \mu \mathrm{m}$, $L=5.25 \mu \mathrm{m}$ ), Ricaniidae (Fig. 11e-h, sensilla no. 1, 2, 7, $L=5.5 \mu \mathrm{m}, L=7.1 \mu \mathrm{m}, L=6.2 \mu \mathrm{m})$, Dictyopharidae (Fig. 17d-f, sensilla no. $1-9, L=4.4 \mu \mathrm{m}, L=5.6 \mu \mathrm{m}$ ), Fulgoridae (Fig. 18c, d, sensilla no. $7-10, L=5.6 \mu \mathrm{m}$ ) and Tettigometridae (Fig. 19b, c, sensilla no. 1-12, $L=7.8 \mu \mathrm{m})$.

Peg sensilla, uniporous (PGSU2, Fig. 2g) Short coneshaped sensilla $(1.0-5.0 \mu \mathrm{m})$ with a rounded tip. This type of sensillum is common in many taxa: Delphacidae (Fig. 5e, f, g, sensilla no. 1-5, 7, $L=2.4 \mu \mathrm{m}$ ), Cixiidae (Fig. 6c-f, sensilla no. 1-7, 9, 10, $L=2.1 \mu \mathrm{m}, L=$ $2.3 \mu \mathrm{m}$ ), Achilidae (Fig. 7e-h, sensilla no. 2, 3, 4, 5, 7, 9, $L=2.75 \mu \mathrm{m}, \quad L=4.25 \mu \mathrm{m}$ ), Meenoplidae (Fig. 8e-h, sensilla no. 1-7, 9-10, $L=3.1 \mu \mathrm{m}$ ), Kinnaridae (Fig. 9d, f, g, sensilla no. 1-7, 9-10, $L=1.6 \mu \mathrm{m}$ ), Derbidae (Fig. 10bf, sensilla no. $1-10, L=3.5 \mu \mathrm{m}, L=2.6 \mu \mathrm{m})$, Ricaniidae (Fig. 11e-h, sensilla no. 3-6, 9, 10, $L=4.2 \mu \mathrm{m}, L=$ $4.5 \mu \mathrm{m}, L=4.05 \mu \mathrm{m}, L=3.1 \mu \mathrm{m} L=3.2 \mu \mathrm{m})$, Flatidae (Fig. 13g, $L=2.3 \mu \mathrm{m}$ ), Tropiduchidae (Fig. 14b-f, sensilla no. 4-12, $L=3.2 \mu \mathrm{m}$ ), Lophopidae (Fig. 15b, c, f, sensilla no. 31-33, $L=3.9 \mu \mathrm{m}$ ), Nogodinidae (Fig. 16d, e, sensilla no. 1-7, 9) and Fulgoridae (Fig. 18d, sensilla no. $1-6, L=4.3 \mu \mathrm{m}, L=4.4 \mu \mathrm{m})$.

Clavate sensilla, uniporous (CLSU, Fig. 2h) These sensilla are similar to peg sensilla except distally enlarged (Fig. 12c, e, sensillum no. 8). Length $2.0 \mu \mathrm{m}$ long (Fig. 12g). Only observed in Issidae.

\section{Mechanoreceptive NP sensilla: tactile sensilla of the labium}

Sensilla chaetica $(\mathrm{CH})$ are the most abundant types of sensilla found on the labium in Fulgoromorpha (Fig. 3a).
On the apical segment, they occur in different lengths and are articulated by a connective membrane to the cuticule (Fig. 3b). They exhibit grooved surfaces without pore (Fig. 3a, c). Based on their length, shape and surface morphology, three types are differentiated as follows:

Large $(45->100 \mu \mathrm{m})$ sensilla chaetica $(\mathrm{CH} 1)$ - The sensilla are long, relatively straight, gradually tapering and slightly curved at the tip (Fig. 3d, e).

Medium length $(20-45 \mu \mathrm{m})$ sensilla chaetica $(\mathrm{CH} 2)-$ Shorter than $\mathrm{CH} 1$, with a fine tip and a strong base and running parallel to the surface (Fig. 3a, d).

Short $(1-10 \mu \mathrm{m})$ sensilla chaetica $(\mathrm{CH} 3)$ - Short with sharp ends (Fig. 3d).

\section{Olfactory and thermoreceptive MP sensilla: subapical} labial sensilla

On each side and near the tip of the labium, there is one (or more) pair of sensilla that are multiporous, suggesting an olfactory and thermo-reception function. According to their shape, three main types are recognized as follows:

- an elevated, cone-like to tubular sensilla (Sa-ECLT) of $15.5 \mu \mathrm{m}$ length (Fig. 4a-c).

- a branched or multilobated tubular sensilla of 8.0 um length (Sa-TEBM) (Fig. 4d).

- a placoid flattened sensilla (Sa-PFPL), peg-like, slightly convex or concave, surrounded by a double furrow (Fig. 4e-i). In Flatidae, the surface of the placoid (Sa-PMPL) has numerous minute $1 \mu \mathrm{m}$ lobes (Figs. 4j, 13a, b).

\section{Discussion}

This paper presents the first comparative analysis of the labial sensilla in planthoppers. Although the studied examples of each family are small, some new and interesting general features are shown.

The planthopper labial sensory ground plan

The sensory equipment in planthoppers consists of wellknown mechanoreceptor sensilla chaetica plus specialized areas/structures: the paired subapical sensory labial organs and the apical sensory labial area. With respect to the latter, the total number of sensilla at the tip of the labium allows us to recognize two main groups in Fulgoroidea. The first group exhibits 12-19 sensilla pairs (12 in meenoplids, derbids and achilids, 13 in cixiids, delphacids, dictyopharids and kinnarids, 14 in tettigometrids, 15 in tropiduchids and issids, 16 in nogodinids and 19 in ricaniids), and 
the second group shows a greater number of pairs (32 in flatids and 35 in lophopids and fulgorids). See Table 2.

According to the currently accepted phylogenies of Fulgoroidea (reviewed in Bourgoin et al. 1997; Urban and Cryan 2007), it seems that the first group of families (noted above) is usually placed at the base of the phylogeny and therefore might represent the plesiomorphic condition. With the exception of the 6 sensilla basiconica (BSN1) observed in the ricaniid representative (that probably represent a specialized condition), the planthopper ground plan should therefore be represented by two pairs of sensory fields:

1. dorsal paired sensory fields with 11 pairs of sensilla (10 peg-like pairs +1 specialized pair dome or cupola-like)

2. ventral impair or paired sensory field with 2 pairs of sensilla basiconica.

The second group of families (noted above) is therefore to be regarded as advanced. The Fulgoridae have retained the 10 dorsal peg-like pairs (as in dictyopharids) completed by a great number of bristle-like sensilla (10 dorsal and 15 ventral pairs). Two families have increased their number of sensilla basiconica, that is, Lophopidae, with only sensilla basiconica distributed in 35 pairs, a pattern approached by the flatids with 17 peg-like and 17 sensilla basiconica pairs.

It is probable that the eleventh specialized pair of dorsal sensilla (either clavate, dome-like or cupola-like) should be regarded as evolved from a more plesiomorphous peg-like sensillum.

This planthopper ground plan can be compared to what is already known in other Hemiptera groups. In Sterrnorhyncha, the labial tip in Aleyrodoidea has seven pairs of sensilla (chemosensitive and contact chemoreceptive) according to a scheme apparently similar among species and sexes (Walker and Gordh 1989); in Psylloidea, four pair peg-like sensilla have been reported, but their exact function remains unknown (Garzo et al. 2012), and in Aphidoidea, only mechanoreceptive sensilla (eight or seven pairs) are present (Wesler 1977; Tjallingii 1978).

In other Auchenorrhyncha, a trend toward a reduction of sensilla seems to have taken place (Leopold et al. 2003; Backus 1988), but a significant variation in type and distribution of sensilla has also been observed (Brożek in prep.).

In Heteroptera, the labial sensilla have been studied in more than 70 species (Beck et al. 1958; Schoonhoven and Henstra 1972; Peregrine 1972; Cobben 1978; Avé et al. 1978; Gaffal 1981; Backus 1988; Rani and Madhavendra 1995; Ventura et al. 2000; Ventura and Panizzi 2005; Brożek 2008; Brożek and Chłond 2010).

In most of these species, the sensilla are more or less numerous and of different shape and size, allowing us to recognize both chemosensitive sensilla (gustatory, contactchemoreceptive) and mechanoreceptive sensilla. In Reduviidae, it has been shown that interspecific variability and intraspecific similarity in the shape and numbers of labial sensilla have potential usefulness as taxonomic/diagnostic characters (Català 1996; Brożek and Chłond 2010).

The above results confirm a ground plan of seven pairs of sensilla in Sternorrhycnha to a richer and more diverse sensory equipment in Auchenorrhycnha, particularly in planthoppers and Heteroptera as noted by Backus (1988).

The labial sensilla in planthoppers

As noted above, this study reveals for the first time the diversity of sensory structures on the labial tip and their grouping into sensory fields in Fulgoromorpha. More taxa need to be studied before trying to present some general scheme at the family level, but some specific morphological types and their distribution seem characteristics of certain groups.

- Disparity of the apical labial sensilla: From the ground plan proposed for planthoppers (10 peg-like dorsal pairs +1 dome or cupola-like dorsal pair +2 sensilla basiconica ventral pairs), the great disparity reported in Table 2 suggests that it is the result of several independent evolutionary events from one plesiomorphic sensilla type, probably peg-like. Only more data/ taxa analyzed in a precise phylogenetical framework will allow us to understand how theses types have evolved.

- Distribution of the apical labial sensilla: At this stage, and according to their distribution, three patterns can be suggested.

The general cixiid pattern (Cixiidae, Delphacidae, Achilidae, Meenoplidae, Kinnaridae, Dictyopharidae, Derbidae and Tettigometridae) Apical sensilla are clearly arranged in two sensory fields (Table 3). The number of the sensilla ranges from 12 to 13 pairs. According to the samples, only minor differences are observed and concern the type and number of sensilla. Among the more specific types of sensilla, the dome-shaped multiporous sensilla are absent in Meenoplidae and probably replaced by its homologous cupola-shaped sensilla. The peg-in-pit uniporous sensillum present in Delphacidae, Cixiidae, Achilidae and Kinnaridae has not been seen in Meenoplidae. In Dictyopharidae and Tettigometridae, the uniporous peg sensilla (PGSU2) are replaced by longer sensilla (PGSU1). Sensilla basiconica (BSN1, BSN2) are found in the above families only in the ventral sensory field.

In Derbidae, apical sensilla are distinctly grouped in three areas, a very probable apomorphic condition. Twelve 
Table 3 Distribution of the different apical sensilla in selected fulgoromorphan families

\begin{tabular}{ll}
\hline Families and species & Types of the sensilla and their distribution \\
\hline Delphacidae & Dorsal sensory field (SF-D) convex: \\
Peregrinus maidis (Ashmead, & $8 \mathrm{PGSU}$ 2, uniporous peg sensilla, short \\
$1890)$ & $1 \mathrm{PGSU}$ 1, uniporous peg sensilla, long \\
See Fig. 5a-f & $1 \mathrm{PPSU}$, uniporous peg-in-pit sensilla \\
& $1 \mathrm{DSSM}$, multiporous dome-shaped sensilla \\
& Ventral sensory field (SF-V) - unpair, convex: \\
& 2 BSN2, sensilla basiconica, short
\end{tabular}

\section{Cixiidae}

Myndus taffini

Bonfils, 1983

Fig. 6a-d

Brixidia boukokensis

Synave, 1958

Fig. $6 \mathrm{e}-\mathrm{f}$

Achilidae

Ballomarius kawandanus

Fennah 1950

Fig. $7 \mathrm{c}-\mathrm{f}$

\section{Meenoplidae}

*Kermesia immaculata Muir, 1927 ,

Fig. 8a Nisia nervosa (Motchulsky, 1863)

Fig. $8 b-h$

Kinnaridae

*Southia capnorhina Fennah, 1980, Fig. 9a

*Atopocixius major Fennah, 1945, Fig. 9b Nesomircixia insularis

Synave, 1958

Fig. $9 \mathrm{c}-\mathrm{h}$
Dorsal sensory field (SF-D) concave:

9 PGSU2, uniporous peg sensilla, short

1 DSSM, multiporous dome-shaped sensilla

1 PPSU, uniporous peg-in-pit sensilla

Ventral sensory field (SF-V) concave:

2 BSN2, sensilla basiconica, short

Dorsal sensory field (SF-D) convex:

6 PGSU2, uniporous peg sensilla, short

2 PGSU1, uniporous peg sensilla, long

1 DSSM, multiporous dome-shaped sensilla

1 PPSU, uniporous peg-in-pit sensilla

Ventral sensory field (SF-V) convex:

1 BSN1, sensilla basiconica, long

1 BSN2, sensilla basiconica, short

Dorsal sensory field (SF-D) convex:

9 PGSU2, uniporous peg sensilla, short

1 CUSM, multiporous cupola-shaped sensilla

Ventral sensory field (SF-V) unpair, convex:

2 BSN2, sensilla basiconica, short

Dorsal sensory field (SF-D) convex:

9 PGSU2, uniporous peg sensilla, short

1 DSSM, multiporous dome-shaped sensilla

1 PPSU, peg-in-pit uniporous sensillum

Ventral sensory field (SF-V) convex:

1 BSN1, sensilla basiconica, long

1 BSN2, sensilla basiconica, short
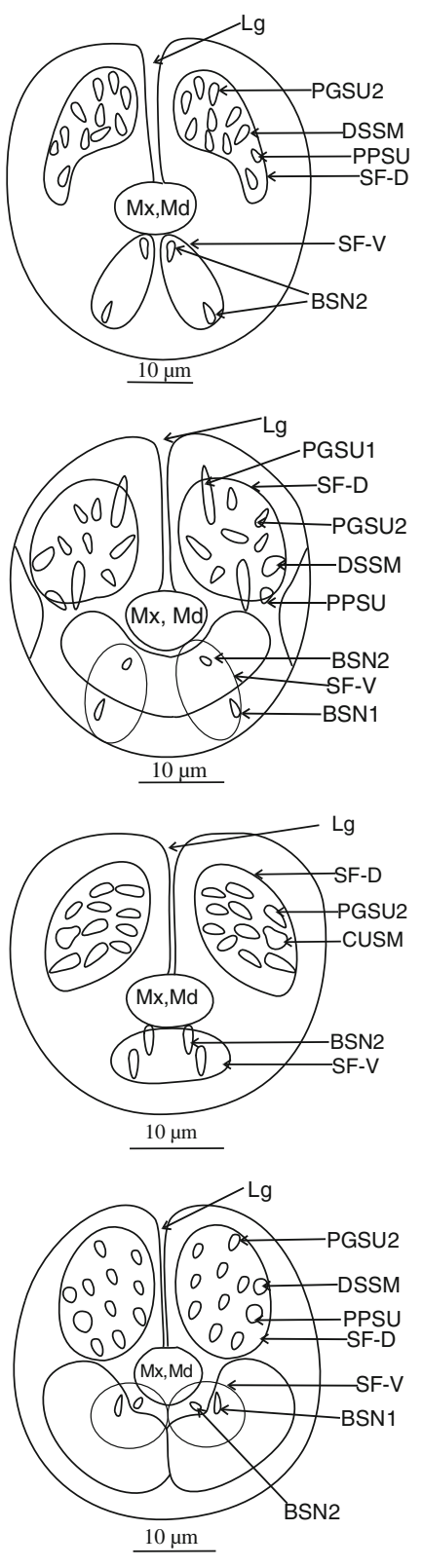
Table 3 continued

\begin{tabular}{ll}
\hline Families and species & Types of the sensilla and their distribution \\
\hline Derbidae & Dorsal sensory field (SF-D) is divided into flat fields A and B: \\
Proutista fritillaris & 4 PGSU2, uniporous peg sensilla, short (SF-D-A) \\
(Boheman,1838) & $6 \mathrm{PGSU}$ 2, uniporous peg sensilla, short (SF-D-B) \\
Fig. 10b-g & $1 \mathrm{PPSU}$, peg-in-pit uniporous sensillum \\
& Ventral sensory field (SF-V) unpair, flat: \\
$1 \mathrm{BSN}$, sensilla basiconica, short
\end{tabular}

Ricaniidae

Pochazia fuscata

Fabricius, 1803

Fig. 11a-h

Issidae

Trienopa paradoxa

(Gerstaecker, 1892)

Fig. $12 b-c$

Flatidae

Flatia sp.

(Schmidt, 1912)

Fig. $13 \mathrm{c}-\mathrm{h}$

Tropiduchidae

*Tropiduchus arisba Fennah, 1958

Fig. $14 \mathrm{a}$

Numicia hulstaerti

(Synave, 1962)

Fig. 14b-d

*Tambinia sp. Stål, 1859

*Kalitaxilana sp. Kirkaldy, 1901
Dorsal sensory field (SF-D) concave:

6 PGSU2, uniporous peg sensilla, short

3 PGSU1, uniporous peg sensilla, long

1 PGSM, multiporous peg sensilla

6 BSN1, sensilla basiconica, long

Ventral sensory field (SF-V) concave:

1 BSN1, sensilla basiconica, long

2 BSN2, sensilla basiconica, short

Dorsal sensory field (SF-D) convex:

1 PGSMC, complex, multiporous peg sensilla,

8 CLSU), uniporous clavate sensilla

4 BSN2, sensilla basiconica, short

Ventral sensory field (SF-V) convex:

2 BSN1, sensilla basiconica, long

Apical sensilla are scattered widely on the labial tip. The boundary between the upper and ventral sensory fields is almost not visible because the sensilla occupy the entire tip surface of the labium.

Dorsal sensory field (SF-D) concave:

16 PGSU2, uniporous peg sensilla, short

1 PGSM, multiporous peg sensillum

Ventral sensory field (SF-V) concave:

3 BSN2, sensilla basiconica, short

12 BSN1, sensilla basiconica, long are distributed on the edge, around the dorsal sensory field

Dorsal sensory field (SF-D) concave is more extended and reaches laterally to the mandibular $(\mathrm{Md})$ and maxillary stylets $(\mathrm{Mx})$ :

9 PGSU2, uniporous peg sensilla, short

1 PGSM, multiporous peg sensila

3 BSN2, sensilla basiconica, short

1 BSN1, sensilla basiconica, long

Ventral sensory field (SF-V) concave:

1 BSN2, sensilla basiconica
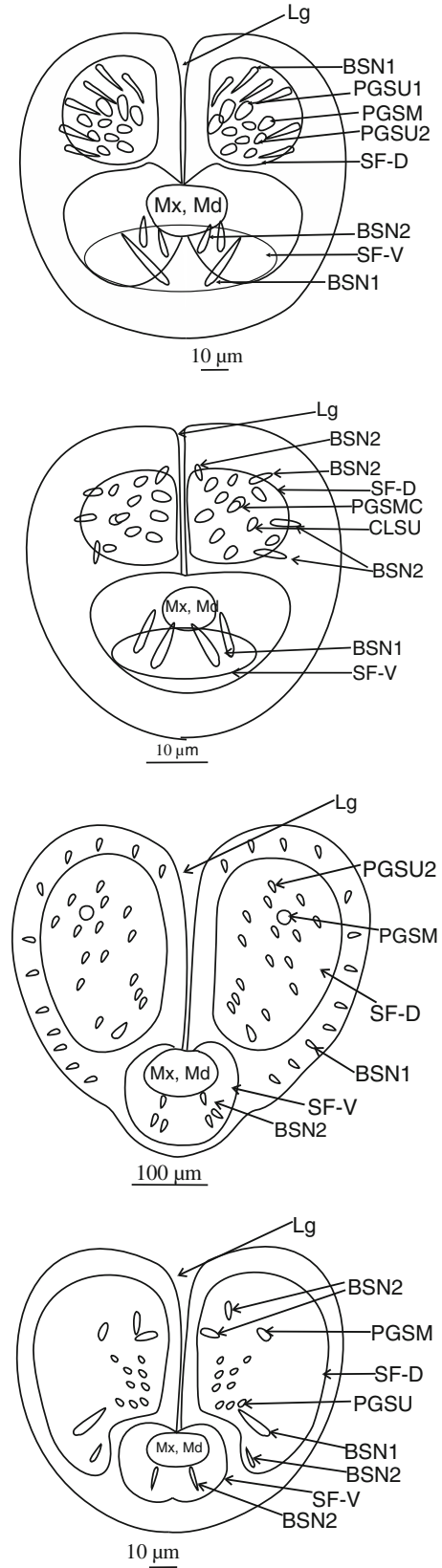
Table 3 continued

\begin{tabular}{|c|c|c|}
\hline Families and species & Types of the sensilla and their distribution & Scheme of the apical tip of labium \\
\hline $\begin{array}{l}\text { Lophopidae } \\
\text { Lophops africana } \\
\text { (Schmidt, 1912) } \\
\text { Fig. 15a-h }\end{array}$ & $\begin{array}{l}\text { Dorsal sensory field (SF-D) concave: } \\
17 \text { BSN2, sensilla basiconica, short } \\
1 \text { BSN1, sensilla basiconica, long between the dorsal sensory field } \\
\text { and the maxillary and mandibular stylets } \\
\text { Ventral sensory field (SF-V) concave: } \\
3 \text { PGSU2, uniporous peg sensilla, short } \\
13 \text { BSN2, sensilla basiconica, short } \\
1 \text { BSN1, sensilla basiconica, long }\end{array}$ & $\begin{array}{l}\text {-SF-D } \\
\text {-BSN2 }\end{array}$ \\
\hline $\begin{array}{l}\text { Nogodinidae } \\
\text { Nogodina reticulata } \\
\text { Fabricius, } 1803 \\
\text { Fig. 16d-h }\end{array}$ & $\begin{array}{l}\text { Dorsal sensory field (SF-D) convex: } \\
8 \text { PGSU2, uniporous peg sensilla, short } \\
1 \text { PGSM, multiporous peg sensilla } \\
2 \text { BSN1, sensilla basiconica, long } \\
1 \text { OPSM, multiporous oval plate sensilla, they are between the } \\
\text { dorsal sensory field and the maxillary and mandibulary stylets } \\
\text { Ventral sensory field (SF-V) convex: } \\
2 \text { BSN1, sensilla basiconica, long } \\
2 \text { BSN2, sensilla basiconica, short }\end{array}$ & $\begin{array}{l}\text { SSN1 } \\
\text { PGSU2 } \\
\text { PGSM } \\
- \text { SF-D } \\
-O P S M\end{array}$ \\
\hline $\begin{array}{l}\text { Dictyopharidae } \\
\text { Afronersia dionacea } \\
\text { Fennah, } 1958 \\
\text { Fig. } 17 \mathrm{c}-\mathrm{h}\end{array}$ & $\begin{array}{l}\text { Dorsal sensory field (SF-D) convex: } \\
9 \text { PGSU1, uniporous peg sensilla, long } \\
1 \text { PGSM, multiporous peg sensillum } \\
\text { Ventral sensory field (SF-V) convex: } \\
2 \text { BSN2, sensilla basiconica, short } \\
1 \text { BSN1, sensilla basiconica, long }\end{array}$ & $\begin{array}{l}\text {-SF-D } \\
\text {-PGSM } \\
\text {-PGSU1 }\end{array}$ \\
\hline $\begin{array}{l}\text { Fulgoridae } \\
\text { Calyptoproctus sp. } \\
\text { Fig. 18b-h }\end{array}$ & $\begin{array}{l}\text { Sensilla are numerous and densely arranged in both sensory fields. } \\
\text { Dorsal sensory field (SF-D) convex: } \\
6 \text { PGSU2, uniporous peg sensilla, short } \\
3 \text { PGSU1, uniporous peg sensilla, long } \\
1 \text { PGSM, multiporous peg sensilla } \\
6 \text { BRSN2, uniporous, bristle-like sensilla, short } \\
4 \text { BRSN1, uniporous, bristle-like sensilla, long } \\
\text { Ventral sensory field (SF-V) convex: } \\
4 \text { BRSN2, uniporous, bristle-like sensilla, short } \\
11 \text { BRSN1 uniporous, bristle-like sensilla, long }\end{array}$ & $\begin{array}{l}\text { BRSN2 } \\
\text { BgSM } \\
\text { PGSU1 } \\
\text { BRSN1 } \\
\text { PGSU2 } \\
\text { BF-D } \\
\text { BRSN2 } \\
\text { BRF-V } 1\end{array}$ \\
\hline
\end{tabular}


Table 3 continued

\begin{tabular}{ll}
\hline Families and species & Types of the sensilla and their distribution \\
\hline Tettigometridae & Dorsal sensory field (SF-D) convex: \\
Tettigometra sulphurea & $12 \mathrm{PGSU}$ 1, uniporous, peg sensilla, long \\
Mulsant \& Rey, 1855 & Ventral sensory field (SF-V) convex: \\
Fig. 19a-c & $2 \mathrm{BSN}$ 2, sensilla basiconica, short \\
*Euphyonarthex phyllostoma & \\
Schmidt, 1912 & \\
Fig. 19d &
\end{tabular}

On each sensory field (right and left), the sensilla are arranged symmetrically with the number of sensilla given for one side

pairs of sensilla are observable. The dorsal sensory field is subdivided into two fields (marked as A and B, Fig. 10b). The lower one (B) is located laterally in relation to the maxillae and mandibles. A characteristic feature is the presence of the uniporous peg-in-pit sensillum (PPSU) in the lower dorsal field. Sensilla basiconica (BSN2) occur only in the ventral sensory field. This specialized derbid pattern has very probably evolved from the general cixiid one.

The general issid pattern (Issidae, Nogodinidae, Tropiduchidae, Ricaniidae and Lophopidae?) Apical sensilla are distinctly grouped into two sensory fields. A number of the sensilla range from 15 to 23 pairs. Sensilla basiconica (BSN1, BSN2) are present in the dorsal and ventral sensory fields. In the Tropiduchidae, Nogodinidae and Ricaniidae representatives, a multiporous peg sensillum (PGSM) is observed, probably homologous with the issid multiporous complex peg sensillum (PGSMC). In addition, in the Issidae species, a specific shaped uniporous peg sensilla (clavate with enlarged tip) is found.

A unique arrangement of two sensilla located between the dorsal sensory field and the opening of the maxillae and mandibles is observed in the Nogodinidae (OPSM). A similar position of the BSN1 is found in Lophopidae which is also unique in its uniporous peg sensilla in the ventral sensory field and the great number of sensilla basiconica in the ventral sensory field. This represents a specialized pattern (lophopid pattern) that has probably evolved from the issid one.

The specialized flatid and fulgorid patterns (Flatidae, Fulgoridae) In these families, apical sensilla are arranged in two sensory fields, but the boundaries between the fields are difficult to trace due to the numerous sensilla (32-35 pairs) that cover the entire labial tip surface, especially sensilla basiconica and bristle-like sensilla. Further studies are necessary to evaluate these patterns that have probably evolved independently.

Sensilla chaetica Recognition of 3 types of sensilla chaetica according to the length is an unexpected result. The medium type (CH2) seems the more largely distributed within the samples and might represent the plesiomorphic type from which evolutionary specialization has occurred toward shorter $(\mathrm{CH} 3)$ or longer sensilla $(\mathrm{CH} 1)$. In other parts of the insect body, mechanosensitive sensilla are of wide occurrence, so it is possible that the subdivisions proposed here may need to be revised when these are studied further.

In the studied sample, the distribution of the three types of sensilla on the labial tip differs greatly as follows. Only type $\mathrm{CH} 3$ was present in Meenoplidae (Fig. 8b) and only type $\mathrm{CH} 2$ occured in Achilidae (Fig. 7a), Kinnaridae (Fig. 9c), Tropiduchidae (Fig. 14b) and Tettigometridae (Fig. 19a), while both these types were present in Delphacidae (Fig. 5a) and Cixiidae (Fig. 6a). Types $\mathrm{CH} 1$ and $\mathrm{CH} 2$ were noticed in Ricaniidae (Fig. 11b), Issidae (Fig. 12a), Lophopidae (Fig. 15a), Nogodinidae (Fig. 16c), Dictyopharidae (Fig. 17a, c) and Fulgoridae (Fig. 3a, d, Fig.18a, b). All three types were observed in Derbidae (Fig. 10a) and Flatidae (Fig. 13a).

The subapical labial sensory organ

Sogawa (1977) was the first to report the presence of a paired subapical sensory organ (wrongly named 'labial palpi') along the sides of the labium in some delphacids, represented by a pair of multiporous branched sensilla sunken into a small pit. This subapical sensory organ has since been found in most Fulgoromorpha families by Cobben (1988), Liang (2005) and in this study and also 
found in the 1st larval stage in Cixiidae (Thierry Bourgoin, unpublished data).

All types observed are multiporous sensilla. The elevated, cone-like or tubular sensilla types were found in Cixiidae (Figs. 4a, 6a, b, e), Meenoplidae (Figs. 8a, b, 4b), Kinnaridae (Fig. 9a, b), Lophopidae (Figs. 4c, 15a) or Tettigometridae (Fig. 19d). The tubular branched shape (Fig. 5b) could represent an autapomorphic character for Delphacinae (Cobben, 1988). The last placoid flattened type was observed in Achilidae (Figs. 4e, 7a, b), Dictyopharidae (Figs. 4f, 17a, b), Tropiduchidae (Figs. 4g, 14a, b), Ricaniidae (Figs. 4h, 11b) and Nogodinidae (Fig. 4i, $16 a, b)$. In Flatidae, the surface of the placoid was not flattened but multilobated with numerous minute lobes (Figs. 4j, 13a, b). Intriguingly, in several representatives, the sensilla were present in more than one pair, for example, 5 of them (placoid type) were found in Nogodinidae (Fig. 16a, b). In Tettigometridae (E. phyllostoma), 2 pairs of sensilla were observed, the anterior one being cone-like (Sa-ECLT) and the posterior represent rounded placoid convex sensilla (Sa-PRCS) (Fig. 19d).

In other Hemiptera, the subapical labial sensory organ seems to be absent in the Cicadomorpha (Cobben 1988), but a very similar cixiid-like structure, called the "batonshaped structure", has been reported on the lateral subapical part of the labium of the bed-bug (Cimex hemipterus) by Singh et al. (1996, Fig. 3e). In the first conservative and parsimonious approach to these observations, we consider that the paired subapical organs are homologous in all planthoppers taxa. This same organ is rather polymorphic and can evolve into quite different shapes or might disappear. Again, according to the currently accepted phylogeny of the group (reviewed in Bourgoin et al. 1997; Urban and Cryan 2007), the organ comprising coneshaped or tubular sensilla would therefore represent the plesiomorphic state (as in Cimex hemiptera), from which at least two new apomorphic-shaped sensilla have evolved: the multi-branched Delphacinae one and the placoid one, each obviously arising independently in several planthopper lineages. The apparent absence of these sensory structures in Derbidae and Fulgoridae needs to be confirmed. The presence of the organ cannot be considered as a possible synapomorphy for the clade [Cixiidae + Delphacidae + Achilixiidae + Achilidae $]$ as stated by Liang (2005) but rather a symplesiomorphy for all Fulgoromorpha, if not a synapomorphy for all the Neohemiptera clade (Fulgoromorpha + Heteropterodea) (Sorensen et al. 1995). However, more morphological studies of the Hemiptera labium in all these groups are needed before positive conclusions can be reached. As suggested already by Cobben (1988), it is possible that, at least for the trunk-feeding fulgorids, the absence of the subapical sensory organs (if confirmed) could be linked to host-plant preference.
Labial sensilla and their function in planthoppers

\section{The labium and the olfactory function}

It is generally accepted that odorant substances, including sex pheromones and host-plant volatiles, diffuse through the wall pores of the multiporous sensilla into the sensillar lymph and are transferred to receptors on the dendrites of specialized neurons by special binding proteins (Leal 2005). In most insects, these olfactory multiporous sensilla occur mainly on the antennae and often on the palps, when these are present. In planthoppers, the characteristic sensory plate organs of the pedicel antenna (Bourgoin and Deiss 1994, reviewed in Stroiński et al. 2011), are very probably in charge of the olfactory function.

In the current study, five multiporous sensilla without flexible sockets have been detected on the labium: the dome-shaped sensilla, the cupola-shaped sensilla, the oval plate sensilla, the peg and the complex peg sensilla. Similar sensilla are known in other hemipteran taxa such as Aleyrodidae (Walker and Gordh 1989) or Heteroptera (Schoonhoven and Henstra 1972; Peregrine 1972; Gaffal 1981), but sometimes also reported as absent (Avé et al. 1978; Hatfield and Frazier 1980; Rani and Madhavendra 1995; Brożek and Chłond 2010). As such types of sensilla are reputed to have an olfactory function (Slifer 1970; Zacharuk 1980; Steinbrecht 1984; Hallberg et al. 2003; Kristoffersen et al. 2006; Onagbola and Fadamiro 2008), one can say that the Hemiptera labium assists the antenna in this function, but the association has not yet been fully studied.

\section{The labium and the gustatory function}

In planthoppers, the dominant group of the sensilla at the tip of the labium is uniporous sensilla: peg sensilla (PGSU1, PGSU2) and, less commonly, peg-in-pit (PPSU) and clavate sensilla (CLSU). The different shapes of the uniporous sensilla on the labium are probably linked to the detection of both physical and various chemical stimuli that are non-volatile or have low volatility, and also through close or direct host contact. All sensilla are located in the dorsal sensory field and belong to the group of gustatory sensilla.

After reviewing Chapman (1982), Backus (1988) pointed out that in heteropteran bugs, information about the volatiles emanating from the surface of plants, and their interaction with the insect cuticle, occurs during the exploration of the plant surface through antennation with the antennal flagellum. It suggests that this occurs through the contact-chemoreceptive sensilla with a gustatory function. In contrast, planthoppers do not antennate the plant during surface exploration, their antennae being too 
small to reach the plant surface. Accordingly, it is likely that the function of plant surface exploration is transferred to the apex of the labium in these insects, during dabbing the plant surface (Backus 1988; Ventura and Panizzi 2005). This evolution belongs to a form of exaptation (an additional new function for a plesiomorphic structure). How this evolution took place remains to be studied but obviously will need to be studied conjointly with the characteristic sensory plate organs of planthopper antennae.

\section{The labium and the contact function}

Ultrastructural studies show that sometimes a mechanoreceptive dendrite may be associated with sensilla that function as contact-chemoreceptive sensilla (Zacharuk 1980; Foster et al. 1983b). Such sensilla, with terminal pore and flexible socket, were not observed during our study, while Foster et al. (1983b) and Backus (1985) mentioned that some of sensilla should be regarded as mechano-chemoreceptive. However, there are difficulties in identifying the two types of sensilla which relies on the presence or absence of the terminal pore. Currently, it is uncertain whether the sensilla basiconica and bristle-like sensilla (BSN1, BSN2, BRSN1, BRSN2) have a terminal pore, although all are embedded in a flexible socket.

Morphological evidence on the labial tip of other hemipterans suggested that contact-chemoreceptive sensilla occur rather frequently in Heteroptera (Schoonhoven and Henstra 1972; Avé et al. 1978; Hatfield and Frazier 1980; Gaffal 1981; Rani and Madhavendra 1995; Rani 2009; Baker et al. 2008) and Aleyrodidae (Walker and Gordh 1989) and Psyllidae (Garzo et al. 2012). Conversely, sensilla basiconica (BSN1, BSN2) that are the second most abundant type of sensillum found on the tip of the labium in Fulgoromorpha are typical mechanoreceptive sensilla. They are generally located in the ventral sensory field below the maxillar and mandibular stylets. They probably assist in positioning the labium during feeding.

\section{The subapical labial sensory organ and its function}

In the delphacids $N$. lugens and $P$. maidis, Foster et al. (1983b) and Backus (1985) reported the presence of many pores on the sensilla of the subapical labial organ, but with a slightly different structure and distribution of dendrites in comparison with the multiporous sensillum on the tip of labium. Their function has not yet been identified.

In several different insects, it has been suggested that sensilla that are recessed from the antennal surface and located within cavities can be involved in measuring humidity and temperature (Steinbrecht 1984; Stange and Stowe 1999; Onagbola and Fadamiro 2008) and may play a role in preventing desiccation (Kristoffersen et al. 2006).
Moreover, similar morphological structures (multilobed or branched sensilla) have also been suggested as possible hydro-receptive or olfacto-receptors (K3 type sensillum) in Coleoptera antennae (Roth and Willis 1951; Meinecke 1975). Accordingly, we provisionally regard them as complex dual functioning sensory organs. However, the placoid type observed in several taxa might operate only for more specialized olfactory functions, as on the antennal flagellum of cicadas (Klein et al. 1988).

\section{Conclusions}

The diverse type, number and distribution of labial sensilla appear much more important than previously supposed. This new set of characters, studied here, allows for the following conclusions:

1. According to the morphological characteristics of the labium sensilla, it appears that they can provide planthoppers with information about tactile, olfactive and gustative stimuli when near or in contact with the plant. The gustatory function appears to be more recently evolved in Auchenorrhyncha compared to other Hemiptera that explore their host-plants by tapping with their antennae. Obviously, these findings will have to be put in perspective with the feeding behavior and diversity of trophic patterns in planthoppers and their host-plant as already observed (Attié et al. 2008).

2. Clearly, this new set of characters brings some interesting evolutionary signal to further studies in taxonomy (identification) and phylogeny of the Fulgoromorpha. While conclusions at this stage are obviously premature, one can already see several issues for further studies:

- From a phylogenetical perspective, will the special types of sensilla observed be representative and autapomorphic of the groups in which they have been found? Is the presence of sensilla basiconica (BSN1, BSN2) in the dorsal sensory field a characteristic only of the higher fulgoroidea families? With more samples studied, will the two main patterns observed be broken into more specialized subdivisions and therefore what phylogenetical value will these smaller divisions have? At a higher level and with a bigger dataset what will be the implications of the presence/absence of the subapical labial sensory organ have for the hemiptera phylogeny?

- From a behavioral perspective: what is the functional signification of the separate pair of sensilla between the dorsal and the ventral sensory field of 
the tip of the labium as observed in the nogodinid and lophopid representatives and of the three sensory fields in derbids? Will they have any value in constructing the phylogeny of these groups? Several representatives show a trend to the multiplication of the sensory units at the tip of the labium, is there any link between this morphology and diet? Can the absence of the subapical sensilla in Fulgoridae really be linked to a different mode of feeding (tree feeding) in these insects?

Acknowledgments We would like to thank the European Commission's Research Infrastructure Action via the Synthesys Project for enabling us to visit the Museum National d'Histoire Naturelle in Paris and for the financial support of this study. We would like also to thank M. Webb from the Natural History Museum in London for reviewing of the manuscript.

Open Access This article is distributed under the terms of the Creative Commons Attribution License which permits any use, distribution, and reproduction in any medium, provided the original author(s) and the source are credited.

\section{References}

Altner H, Prillinger L (1980) Ultrastructure of invertebrate chemo-, termo-, and hygroreceptors and its functional significance. Int Rev Cyt 67:69-139

Attié M, Bourgoin Th, Veslo J, Ad Soulier-Perkins (2008) Patterns of trophic relationships between planthoppers (Hemiptera: Fulgoromorpha) and their host plants on the Mascarene Islands. J Nat Hist 42(23):1591-1638

Avé D, Frazier JL, Hatfield LD (1978) Contact chemoreception in the tarnished plant bug Lygus lineolaris. Entomol Exp Appl 24:17-27

Backus EA (1985) Anatomical and sensory mechanisms of leafhopper and planthopper feeding behavior. In: Nault LR, Rodriguez JG (eds) The leafhoppers and planthoppers. Wiley, New York, pp 163-194

Backus EA (1988) Sensory systems and behaviours which mediate hemipteran plant-feeding: a taxonomic overview. J Insect Physiol 34(3):151-165

Backus EA, McLean DC (1982) The sensory systems and feeding behaviour of leafhoppers. I. The aster leafhopper, Macrosteles fascifrons Stål (Homoptera, Cicadellidae). J Morphol 173:361379

Backus EA, McLean DL (1983) The sensory systems and feeding behavior of leafhoppers. II. A comparison of the sensillar morphologies of several species (Homoptera: Cicadellidae). J Morphol 176:3-14

Backus EA, McLean DL (1985) Behavioral evidence that the precibarial sensilla of leafhoppers are chemosensory and function in host discrimination. Entomol Exp Appl 37:219-228

Baker GT, Chen XP, Ma PWK (2008) Labial tip sensilla of Blissus leucopterus (Hemiptera: Blissidae): ultrastructure and behavior. Insect Sci 15(3):271-275

Beck SD, Edwards CA, Medler JT (1958) Feeding and nutrition of the milkweed bug. Oncopeltus fasciatus (Dallas.). Ann Entomol Soc Am 51:283-288
Bourgoin T, Deiss V (1994) Sensory plate organs of the antenna in the Meenoplidae-Kinnaridae group (Hemiptera: Fulgoromorpha). Int J Insect Morphol Embryol 23:159-168

Bourgoin T, Steffen-Campbell JD, Campbell BC (1997) Molecular phylogeny of Fulgoromorpha (Insecta, Hemiptera, Archaeorrhyncha). The enigmatic Tettigometridae: evolutionary affiliations and historical biogeography. Cladistics 13:207-224

Brożek J (2008) Morphology and arrangement of the labial sensilla of the water bugs. B Insectol 61(1):67-168

Brożek J, Chłond D (2010) Morphology, arrangement and classification of sensilla on the apical segment of labium in Peiratinae (Hemiptera: Heteroptera: Reduviidae). Zootaxa 2476:39-52

Català S (1996) Sensilla associated with the rostrum of eight species of Triatominae. J Morphol 228:195-201

Chapman RF (1982) Chemoreception: the significance of receptor numbers. Adv Insect Physiol 16:247-336

Chapman RF (1995) Regulation of a meal. In: Chapman RF, de Boer $\mathrm{G}$ (eds) Regulatory mechanism in insect feeding. Chapman \& Hall, USA, p 106

Chapman RF (1998) Mechanoreception. Chemoreception. In: Chapman RF (ed) The insects, structure and function, 4th edn. Cambridge University Press, UK, pp 610-652

Chapman RF (2003) Contact chemoreception in feeding by phytophagous insects. Ann Rev Entommol 48:455-484. doi:10.1146/ annurev.ento.48.091801.112629

Cobben RH (1978) Evolutionary trends in Heteroptera. Part II. Mouthpart-structures and feeding strategies. Meded Landbouwhogeschool Wageningen 78-5, pp 91-95

Cobben RH (1988) What do we know about host selection in Auchenorrhyncha? In: Vidano C, Arzone A (eds) Proceedings of the 6th Auchenorrhyncha meeting, Turin, Italy, 7-11 Sept, pp 81-92

Foster S, Goodman LJ, Duckett JG (1983a) Sensory receptors associated with the stylets and cibarium of the rice brown planthopper, Nilapavarta lugens. Cell Tissue Res 232:111-119

Foster S, Goodman LJ, Duckett JG (1983b) Ultrastructure of sensory receptors on the labium of the rice brown planthopper. Cell Tissue Res 230:353-366

Gaffal KP (1981) Terminal sensilla on the labium of Dysdercus intermedius distant (Heteroptera: Pyrrhocoridae). Int $\mathrm{J}$ Insect Morphol Embryol 10(1):1-6

Garzo E, Bonani JP, Lopes JRS, Fereres A (2012) Morphological description of the mouthparts of the Asian citrus psyllid, Diaphorina citri Kuwayama (Hemiptera: Psyllidae). Arthropod Struct Dev 41:79-86

Hallberg E, Hansson BS, Lofstedt C (2003) Lepidoptera, moths and butterflies: morphology, physiology and development. In: Kristensen NP (ed) Sensilla and proprioreceptors, vol 2. Walter de Gruyter, Berlin, pp 267-288

Hatfield LD, Frazier JL (1980) Ultrastructure of the labial tip sensilla of the tarnished plant bug, Lygus lineolaris (P. de Beauvois) (Hemiptera: Miridae). Int J Insect Morphol Embryol 9(1):59-66

Klein U, Bock C, Kafka WA, Moore TE (1988) Olfactory sensilla on the antennae of Magicada cassini (Fisher) (Homoptera, Cicadina): structure, function and possible behavioral role. In: Vidano C, Arzone A (eds) Proceedings of the 6th Auchenorrhyncha meeting, Turin, Italy, 7-11 Sept, pp 93-98

Kristoffersen L, Hallberg E, Walle NR, Anderbrant O (2006) Sparse sensilla array on Trioza apicalis (Homoptera: Triozidae) antennae-an adaptation to high stimulus level. Arthropod Struct Dev 35:85-92

Leal WS (2005) Pheromone reception. In: Schulz S (ed) The chemistry of pheromones and other semiochemicals II (topics in current chemistry). Springer, New York, pp 1-36

Leopold RA, Freeman ThO, Buckner JS, Nelson DR (2003) Mouthpart morphology and stylet penetration of host plants by 
the glassy winged sharpshooter, Homalodisca coagulata, (Homoptera: Cicadellidae). Arthropod Struct Dev 32:189-199

Liang AP (2005) Occurrence of the latero-subapical labial sensillum in Borysthenes maculata and Andes marmorata (Hemiptera: Fulgoromorpha: Cixiidae). J Entomol Sci 40:428-437

Meinecke C (1975) Riechsensillen und Systematik der Lamellicornia (Insecta Coleoptera). Zoomorphologie 82:1-42

Miles PW (1958) Contact chemoreception in some Heteroptera, including chemoreception internal to the stylet food canal. J Insect Physiol 2:338-347

Mora R, Retana A, Espinoza AM (2001) External morphology of Tagosodes orizicolus (Homoptera: Delphacidae) revealed by scanning electron microscopy. Ann Entomol Soc Am 94:438-448

Onagbola EO, Fadamiro HY (2008) Scanning electron microscopy studies of antennal sensilla of Pteromalus cerealellae (Hymenoptera: Pteromalidae). Micron 39:526-535

Peregrine DJ (1972) Fine structures of sensilla basiconica on the labium of the cotton stainer, Dysdercus fasciatus (Signoret) (Heteroptera: Pyrrhocoridae). Int J Insect Morphol Embryol 1(3):241-251

Rani PU (2009) Sensillary morphology on the rostral apex and their possible role in prey location behaviour of the carnivorous stinkbug, Eocanthecona furcellata (Wolff) (Heteroptera: Pentatomidae). Acta Zool 90(3):246-256

Rani PU, Madhavendra SS (1995) Morphology and distribution of antennal sense organs and diversity of mouthpart structures in Odontopus nigricornis (Stall) and Nezera viridula L. (Hemiptera). Int J Insect Morphol Embryol 24(2):119-132

Romani R, Stacconi MVR, Riolo P, Isidoro N (2009) The sensory structures of the antennal flagellum in Hyalesthes obsoletus (Hemiptera: Fulgoromorpha: Cixiidae): a functional reduction? Arthropod Struct Dev 38:473-483

Roth CM, Willis ET (1951) Hygroreceptors in Coleoptera. J Exp Zool 117:451-488

Schoonhoven LM, Henstra S (1972) Morphology of some rostrum receptors in Dysdercus spp. Neth J Zool 22(3):343-346

Singh RN, Singh K, Prakash S, Mendkri MJ, Rao KM (1996) Sensory organs of the body parts of the bed-bug Cimex hemipterus Fabricius (Hemiptera: Cimicidae) and the anatomy of its central nervous system. Int J Insect Morphol Embryol 25(1/2):183-204
Slifer E (1970) The structure of arthropod chemoreceptors. Annu Rev Entomol 15:121-142

Sogawa K (1977) Feeding physiology of the brown planthopper. The rice Brown Planthoppers. Food fert Technol Cent Asian Pac Reg Taipei, Taiwan, pp 95-114

Sorensen JT, Campbell BC, Gill RJ, Steffen-Campbell JD (1995) Non-monophyly of Auchenorrhyncha ("Homoptera"), based upon 18S rDNA phylogeny: eco-evolutionary and cladistic implications within pre-Heteropterodea Hemiptera (s.1.) and a proposal for new monophyletic suborders. Pan-Pac Entomol $71: 31-60$

Stange G, Stowe S (1999) Carbon-dioxide sensing structures in terrestrial arthropods. Microsc Res Tech 47:416-427

Steinbrecht RA (1984) Chemo-, hygro-, and thermoreceptors. In: Bereiter-Hahn J, Matoltsy AG, Richards KS (eds) Biology of the integument invertebrates, vol 1. Springer, Berlin, pp 521-553

Stroiński A, Gnezdilov VM, Bourgoin T (2011) Sub-brachypterous Ricaniidae (Hemiptera: Fulgoromorpha) of Madagascar with morphological notes for these taxa. Zootaxa 3145:1-70

Tjallingii FW (1978) Mechanoreceptors of the aphid labium. Entomol Exp Appl 24:531-537

Urban JM, Cryan JR (2007) Evolution of the planthoppers (Insecta: Hemiptera: Fulgoroidea). Mol Phylogenet Evol 42:556-572

Ventura MU, Panizzi AR (2005) Morphology of olfactory sensilla and its role in host plant recognition by Neomegalotomus parvus (Westwood) (Heteroptera: Alydidae). Braz Arch Biol Techn 48(4):589-597

Ventura MU, Montalván R, Panizzi AR (2000) Feeding preferences and related types of behaviour of Neomegalotomus parvus. Entomol Exp Appl 97(3):309-315

Walker GP, Gordh G (1989) The occurrence of apical labial sensilla in the Aleyrodidae and evidence for a contact chemosensory function. Entomol Exp Appl 51:215-224

Wesler RJ (1977) The fine structure of distal receptors on the labium of the aphid, Brevicoryne brassicae L. (Homoptera). Cell Tissue Res 181:409-422

Zacharuk RY (1980) Ultrastructure and function of insect chemosensilla. Annu Rev Entomol 25:27-47 